\title{
Comparison Between Keyhole Weld Model and Laser Welding Experiments
}

B. C. Wood, T. A. Palmer, J. W. Elmer

September 23, 2002

U.S. Department of Energy

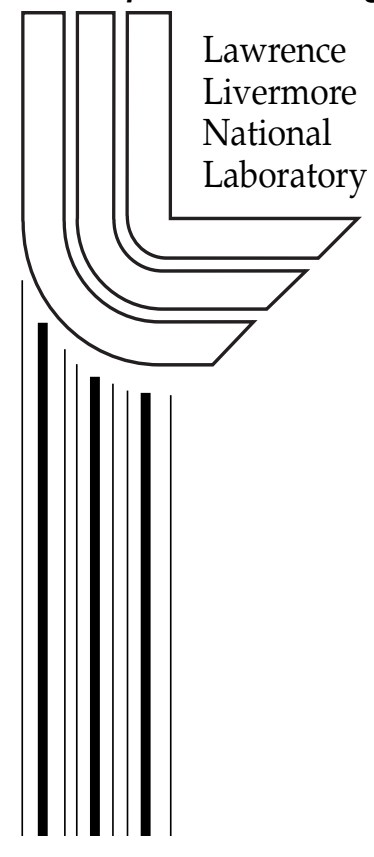




\title{
DISCLAIMER
}

This document was prepared as an account of work sponsored by an agency of the United States Government. Neither the United States Government nor the University of California nor any of their employees, makes any warranty, express or implied, or assumes any legal liability or responsibility for the accuracy, completeness, or usefulness of any information, apparatus, product, or process disclosed, or represents that its use would not infringe privately owned rights. Reference herein to any specific commercial product, process, or service by trade name, trademark, manufacturer, or otherwise, does not necessarily constitute or imply its endorsement, recommendation, or favoring by the United States Government or the University of California. The views and opinions of authors expressed herein do not necessarily state or reflect those of the United States Government or the University of California, and shall not be used for advertising or product endorsement purposes.

This report has been reproduced directly from the best available copy.

Available electronically at http://www.doc.gov/bridge

\author{
Available for a processing fee to U.S. Department of Energy \\ And its contractors in paper from \\ U.S. Department of Energy \\ Office of Scientific and Technical Information \\ P.O. Box 62 \\ Oak Ridge, TN 37831-0062 \\ Telephone: (865) 576-8401 \\ Facsimile: (865) 576-5728 \\ E-mail: reports@adonis.osti.gov \\ Available for the sale to the public from \\ U.S. Department of Commerce \\ National Technical Information Service \\ 5285 Port Royal Road \\ Springfield, VA 22161 \\ Telephone: (800) 553-6847 \\ Facsimile: (703) 605-6900 \\ E-mail: orders@ntis.fedworld.gov \\ Online ordering: http://www.ntis.gov/ordering.htm
}

\section{OR}

Lawrence Livermore National Laboratory

Technical Information Department's Digital Library

http://www.llnl.gov/tid/Library.html 


\title{
Comparison Between Keyhole Weld Model and Laser Welding Experiments
}

\author{
B. C. Wood, T. A. Palmer, and J. W. Elmer \\ Lawrence Livermore National Laboratory \\ Livermore, CA
}

\begin{abstract}
A series of laser welds were performed using a high-power diode-pumped continuous-wave Nd:YAG laser welder. In a previous study, the experimental results of those welds were examined, and the effects that changes in incident power and various welding parameters had on weld geometry were investigated. In this report, the fusion zones of the laser welds are compared with those predicted from a laser keyhole weld simulation model for stainless steels (304L and 21-6-9), vanadium, and tantalum. The calculated keyhole depths for the vanadium and 304L stainless steel samples fit the experimental data to within acceptable error, demonstrating the predictive power of numerical simulation for welds in these two materials. Calculations for the tantalum and 21-6-9 stainless steel were a poorer match to the experimental values. Accuracy in materials properties proved extremely important in predicting weld behavior, as minor changes in certain properties had a significant effect on calculated keyhole depth. For each of the materials tested, the correlation between simulated and experimental keyhole depths deviated as the laser power was increased. Using the model as a simulation tool, we conclude that the optical absorptivity of the material is the most influential factor in determining the keyhole depth. Future work will be performed to further investigate these effects and to develop a better match between the model and the experimental results for 21-6-9 stainless steel and tantalum.
\end{abstract}




\section{Introduction}

All welds were made using a $3.3 \mathrm{~kW}$ Rofin-Sinar diode-pumped Nd:YAG CW laser welder [1] on samples with thicknesses between 0.120 and 0.130 inch with a step joint, as indicated in Fig. 1. The materials welded in these experiments include 21-6-9 stainless steel (18.9 wt. \% Cr, 7.4 wt. \% Ni, 8.8 wt. \% Mn, 0.47 wt. \% Si, 0.03 wt. \% C), 304L stainless steel (18.3 wt. \% Cr, 8.7 wt. \% Ni, 1.9 wt. \% Mn, 0.48 wt. \% Si, 0.02 wt. $\% \mathrm{C}$ ), and commercially pure samples of vanadium and tantalum. Weld powers were varied in $250 \mathrm{~W}$ increments, beginning with $250 \mathrm{~W}$ and ending at the power at which the weld penetrated the entire thickness. In the original experiment, both helium and argon were used as shielding gases, but only those results using helium (at a flow rate of $90 \mathrm{cfh}$ for the steels and vanadium, and $150 \mathrm{cfh}$ for tantalum) are analyzed here because the pertinent data cover a wider range of incident powers. In the case of the vanadium and tantalum samples, the laser head was tilted 10 degrees from normal to avoid backreflection damage to the laser delivery optics. For each run, the beam focal length was $160 \mathrm{~mm}$, the beam radius focused on the surface of the samples was taken to be 0.265 $\mathrm{mm}$, and the beam radius at the end of the lens was estimated to be $25 \mathrm{~mm}$.

Table 1 lists the welding parameters and experimental results for each the keyhole-geometry welds against which simulation results were compared. An initial examination reveals that the steels provide deeper welds at lower input powers than the refractory metals. Tantalum required especially high laser power $(\sim 1500 \mathrm{~W})$ and a slower travel speed (30 in/min) to obtain a keyhole-geometry weld. In this paper, a laser keyhole model is used to analyze the results in Table 1 to provide insight into what factors contribute to the weld penetration.

\section{Laser Keyhole Model}

In recent years, computing technology and numerical techniques have improved to the point where numerical modeling has begun to take shape as a realistic method for the prediction of weld geometries. In part to quantify the predictive power of keyhole weld modeling, we compared the known values for weld depth given in Table 1 with 
values calculated by a simulation based on a simple heat flow model [2]. The simulation is written in FORTRAN and executes on a PC running Microsoft Windows ${ }^{\circledR}$. Typical runtimes on a Pentium 4-class machine are on the order of one minute. Screenshots illustrating the interface and input parameters of the simulation are provided in Fig. 2.

The model uses a heat flux balance at the edge of the keyhole wall in order to estimate the depth and width of the vapor cavity. The following assumptions are made: first, that the keyhole wall temperature is equal to the boiling point of the material; second, that the heat transfer along directions perpendicular to the incident laser beam (parallel to the welding surface) is much faster than along directions parallel to the beam; and third, that the plasma in the keyhole has a constant absorption coefficient, independent of position. The first assumption is reasonable since the system is open to the atmosphere. The second also holds, since the keyhole is nearly vertical, and the keyhole wall temperature is assumed to be equal to the boiling point of the material, giving rise to primarily radial heat transfer away from the laser keyhole. The third assumption has little theoretical justification, but in practice, the energy loss due to absorption in the plasma is quite small for Nd:YAG laser welding, so the overall error in beam intensity due to this approximation is minor, and calculations are simplified considerably.

A schematic illustration of the heat flow at the edge of the keyhole weld is provided in Fig. 3. We begin by requiring a heat flux balance at the keyhole wall, accounting for heat flux transferred into the wall $\left(I_{c}\right)$, local absorption of beam energy $\left(I_{a}\right)$, and heat flux outward due mainly to the heat of evaporation $\left(I_{v}\right)$. The angle, $\theta$, between the beam and the keyhole wall is therefore determined by:

$$
\tan (\theta)=\frac{I_{c}}{I_{a}-I_{v}}
$$

In cylindrical coordinates $(r, \varphi, z)$, with the origin corresponding to the laser beam point of contact with the sample surface and the $z$-axis pointing upward along the beam axis (see Fig. 3), the contribution to the overall heat flux into the keyhole wall is expressed in the following relation: 


$$
I_{c}(r, \varphi)=\lambda_{t h}\left(T_{v}-T_{a}\right)\left(\frac{v}{2 \kappa}\right)\left(\cos \varphi+\frac{K_{1}(v r / 2 \kappa)}{K_{0}(v r / 2 \kappa)}\right)
$$

where $\lambda_{t h}$ is the thermal conductivity, $T_{v}$ is boiling point, $T_{a}$ is the ambient (room) temperature, $v$ is the welding speed, $\kappa$ is the thermal diffusivity, and $K_{n}$ is the second kind and $n^{\text {th }}$ order solution to the modified Bessel function. This relation can be derived from a combination of Rosenthal's model for the temperature profile in an infinite plate due to a moving line source $[2,3]$ and Fourier's law of heat conduction, under the assumptions that heat flow along the beam axis (the $z$ direction) is negligible, and that the keyhole wall temperature is equal to the material's boiling point. The heat flux at the front and rear of the keyhole walls can be found by substituting $\varphi=0$ and $\varphi=\pi$, respectively.

The weld depth is further dependent upon the heat flux at the keyhole wall due to the optical absorption of laser power directly into the material. To a first approximation, the heat flux due to Fresnel absorption $\left(I_{a}\right)$ is shown below:

$$
I_{a}(r, \varphi, z)=\alpha I_{0}(r, \varphi, z)
$$

where $I_{0}$ is the local power intensity of the beam and $\alpha$ is the Fresnel absorption coefficient (absorptivity). The local power density $I_{0}$ can be calculated using the following relation:

$$
I_{0}(r, \varphi, z)=I_{f 0}\left(\frac{r_{f 0}}{r_{f}}\right)^{2} \exp \left(-\frac{r^{2}}{r_{f}^{2}}\right) \text {. }
$$

where $I_{f 0}$ is the peak intensity at the focal point, given by $\frac{2 P}{\pi r_{f 0}^{2}}$, where $P$ is the incident laser power and $r_{f 0}$ is the beam radius at the focal point; and $r_{f}$ is the local beam radius, given by:

$$
r_{f}=r_{f 0}\left[1+\left(\frac{z+z_{0}}{2 f r_{f 0} / d_{b}}\right)^{2}\right]^{1 / 2}
$$

where $z_{0}$ is the beam defocusing, $f$ is the beam focal length, and $d_{b}$ is the beam diameter at the lens. 
The Fresnel absorption coefficient, $\alpha$, depends on the incident laser wavelength, sample surface geometry, joint geometry, and the nature of the plasma present above the weld pool. In practice, directly tabulated values of $\alpha$ are difficult to obtain, but a reasonable approximation for incident wavelengths in the infrared by relating the absorptivity to the temperature-dependent value of the electrical resistivity according to the following equation: [4]

$$
\alpha=0.365\left(\frac{\rho}{\lambda}\right)^{1 / 2}-0.0667\left(\frac{\rho}{\lambda}\right)+0.006\left(\frac{\rho}{\lambda}\right)^{3 / 2}
$$

where $\rho$ is the resistivity $(\Omega-\mathrm{cm})$ and $\lambda$ is the incident laser wavelength $(\mathrm{cm})$. This relation recognizes that the absorption of infrared radiation in metals is dependent largely upon conductive absorption by free electrons. It should be noted that the approximation is valid only for clean metal surfaces and neglects absorptivity contributions due to surface effects. The assumption is reasonable for the keyhole, since the laser is directly interacting with the molten metal.

Yet the expression for the heat flux due to optical absorption, $I_{a}$, fails to take into account the possibility of multiple reflections inside the keyhole cavity. If a portion of the laser power is not absorbed upon first incidence at the keyhole wall but is instead reflected, there is a chance it may be absorbed upon second incidence, and so forth. As a result, the actual absorbed power is much higher than is directly predicted by the Fresnel absorption, which accounts for only a single reflection. The inclusion of multiple reflections into the model will be discussed later.

In addition, the above treatment fails to account for interactions of the laser with the plasma above the weld pool, which can significantly affect the optical absorptivity inside the keyhole. Free electrons traveling through the plasma's electric field can absorb additional kinetic energy via direct photon absorption from the laser beam. This phenomenon is known as inverse Bremsstrahlung. [3,5]

If we include energy absorption from the laser beam due to inverse Bremsstrahlung and the possibility of additional Fresnel absorption due to multiple reflections, we can replace Eq. 3 with a modified expression for the overall heat flux due to optical absorption effects: 


$$
I_{a}=e^{-\alpha_{p} z}\left[1-(1-\alpha)^{\left(1+\frac{\pi}{4 \bar{\theta}}\right)}\right] I_{0}
$$

where $\alpha_{p}$ is the so-called inverse Bremsstrahlung absorption coefficient, expressions for which have been obtained by ZelDovich and Raizer [6] but will not be discussed here, and $\bar{\theta}$ is the mean angle of the keyhole wall. In the code, a first round of calculations is performed without these two effects in order to obtain estimates of the heat fluxes and local keyhole wall angles before they are included in the final calculation.

The evaporative heat flux on the keyhole wall is given by summing over the $n$ individual elements in the alloy:

$$
I_{v}=\sum_{i=1}^{n} J_{v, i} \Delta H_{v, i}
$$

where $\Delta H_{v, i}$ is the heat of evaporation of the $i^{\text {th }}$ alloying element and $J_{v, i}$ is the evaporation flux, estimated for each alloying element by a modified Langmuir equation:

$$
J_{v, i}=\frac{44.34}{7.5} a_{i} P_{i}^{0}\left(T_{v}\right) \sqrt{\frac{M_{i}}{T_{v}}}
$$

where $a_{i}$ is the activity of the $i^{\text {th }}$ element in the liquid alloy (taken to be its atomic fraction in the alloy), $M_{i}$ is the molecular weight of that element, and $P_{i}^{0}\left(T_{v}\right)$ is the element's equilibrium vapor pressure over pure liquid at the boiling point, $T_{v}$. The unmodified Langmuir equation considers evaporation in a vacuum, but in the presence of atmospheric pressure, evaporation rates are suppressed. As a result, the factor of 7.5 has been included based on previous experimental and modeling studies at Penn State [7-10], in which the Langmuir equation is found to consistently overpredict the calculated evaporation flux by a factor of 5 to 10 at one atmosphere pressure.

The simulation code first estimates the distances between the line source (laser beam) and the front and rear keyhole walls at the surface using Rosenthal's line source model. The heat fluxes are then calculated at the surface and substituted into Eq. 1, giving values for the local angles of the front and rear keyhole walls. These angles in turn allow for iterative prediction of the keyhole wall positions for the next depth $z+\Delta z$. The code then calculates the heat fluxes and local angles for this new position, and the process is repeated. Execution terminates when the positions of the front and rear 
keyhole walls converge. This location is then considered to be the keyhole penetration depth. Note that the actual weld depth is actually slightly larger than this value, since the model only calculates radial heat flow outward from the beam axis and does not account for the liquid layer below the vapor cavity. As an example, a sample output of the simulation code showing both the thermal profile and the keyhole geometry is provided in Fig. 4.

\section{Simulation Inputs}

The simulation described above was used to predict keyhole penetration for each of the materials at the weld powers experimentally found to give keyhole-geometry welds. For each simulation, the program requires certain material properties, as well as a set of fundamental welding parameters. As these material properties vary greatly for different materials and provide the only means of differentiation between the metals from the perspective of the simulation, it is vital that reliable values be found.

Table 2 summarizes the material properties required as input for the simulation, as well as corresponding values for vanadium, tantalum, and 304L stainless steel. Many of the properties - most notably, thermal conductivity, specific heat, density, and Fresnel absorption coefficient - are highly temperature dependent. In each case, the numbers were chosen to be as close as possible to the values for the liquid phase just below the boiling point, since we are assuming that the keyhole wall temperature is the boiling point of the material, and the multiple laser reflections within the keyhole make it likely that most of the laser is interacting with a high-temperature liquid. Table 2 does not include values for the 21-6-9 stainless steel, since appropriate temperature-dependent values for the required thermophysical properties are currently unavailable.

Since directly tabulated data for the Fresnel absorption coefficients were unavailable, calculations for this parameter were made by substituting electrical resistivity values for the liquid at the boiling point into Eq. 6. For reference, temperaturedependent resistivities for vanadium, tantalum, and 304L stainless steel are plotted from $100 \mathrm{~K}$ to their respective boiling points in Fig. 5, demonstrating the strong temperature dependence of the resistivity (and, by extension, the optical absorptivity). The values 
used in the absorptivity calculation are indicated on the graph. Moreover, inverse Bremsstrahlung coefficients for the materials examined here were not available. Accordingly, all simulations were run using the default value of 100, which is typical for $\mathrm{CO}_{2}$ laser welding aluminum alloys

The simulation further requires that the elemental composition of the alloy be entered as an input parameter for calculation of the evaporative flux term described by Eq. 8. At this time, the program can only accept alloys of binary composition, as can be seen by examination of Fig. 2. Accordingly, for most runs, the compositions of the stainless steels were approximated as binary alloys of their two primary elemental constituents (by wt. \%)—namely, iron and chromium.

\section{Results and Discussion}

Once the appropriate materials property data were acquired, simulations were run for each material and each welding condition listed in Table 1 to determine the keyhole penetration depth. The results of the simulations for the input material parameters listed in Table 2 are shown in Table 3 and Figs. 6 through 9, which compare the keyhole weld penetration depths as calculated by the simulation to the corresponding experimental values.

\section{Refractory Metals}

The simulation results, along with the corresponding experimental values, are plotted for vanadium in Fig. 6. The calculated values show good agreement with experimental results, particularly at lower powers. When the laser power is increased from $1000 \mathrm{~W}$ to $1250 \mathrm{~W}$, the calculated values for keyhole depth stay close to and just below the experimental values, increasing by approximately the same margin $(\sim 0.3 \mathrm{~mm})$. Some underprediction is expected, since the liquid layer below the vapor cavity is not taken into account by the simulation. As the incident power is further increased, the calculated keyhole depths also increase, although at a slower rate than the experimental results. As a result, there is some discrepancy between simulation and experiment at 
higher powers, but the predictive capability of the simulation for the welding of vanadium is nonetheless apparent.

Results for the tantalum keyhole welds are displayed in Fig. 7. The calculated values show an increase at approximately the same rate as the experimental values when the power is increased from $1500 \mathrm{~W}$ to $1750 \mathrm{~W}$, but upon raising the power to $2000 \mathrm{~W}$, the scaling of the calculated data remains nearly linear, whereas the experimental data does not. In this regard, the trend matches the vanadium. However, unlike the vanadium, the tantalum weld depth is severely underpredicted even at lower powers. At $1500 \mathrm{~W}$, for instance, the calculated keyhole depth is only $\sim 70 \%$ of the experimental value.

This discrepancy between simulation and experiment for the tantalum welds is difficult to account for. The metal's uncharacteristically high melting and boiling points likely contribute (there is more than a $2000 \mathrm{~K}$ difference between the boiling points of tantalum and vanadium), as it is hard to predict what temperatures may be reached inside the keyhole. The beam may be interacting more with the solid and low-temperature liquid than in the case of the other metals, where interactions with the liquid near the boiling point are dominant. As such, the assumption that the keyhole wall temperature is fixed at the boiling point of the material may be inaccurate here.

Moreover, the density of tantalum is much greater than that of vanadium, which could be causing a keyhole collapse not properly accounted for by the model. This property has a further effect of increasing the porosity for the keyhole geometry welds. Indeed, the micrographs of the tantalum welds reveal a high degree of porosity [1]. It is further possible that this plasma absorption coefficient (inverse Bremsstrahlung coefficient) itself differs somewhat for tantalum from the corresponding values for the other metals tested, but since Bremsstrahlung coefficients were unavailable for the materials, this could not be confirmed.

In addition, the shield gas flow rate was higher for the tantalum welds than for any of the other welds performed, which could introduce a systematic error for which the simulation is unable to account. Indeed, our previous report [1] shows that varying the shield gas parameters can have a minor but quantifiable effect on the weld depth, yet there is no obvious way to introduce this factor into the simulation's input parameters. 
Furthermore, it should be noted that for both tantalum and vanadium, there is an additional source of systematic error that is unaccounted for in the simulation. In both cases, the laser beam was tilted at an angle of $10^{\circ}$ from normal incidence during the experiments to ensure that no back-reflection of the laser into the fiber-optic delivery system occurred. Tilting the laser beam increases the cross-sectional area of the incident beam, bringing into question the validity of neglecting the effect of vertical heat transfer on the absorptivity. However, any error introduced by the off-normal incidence should affect vanadium as well as tantalum, yet the vanadium data closely fits the experimental values. This suggests that the effect may in fact be minor, and that the poor fit of the tantalum data does not owe itself to beam angle. Indeed, the dependence of the absorptivity on the incident angle has been quantified for laser welding in iron alloys $[28,29]$ and is shown to be minor, but this effect is material dependent. As a result, extension of these results to $\mathrm{Nd}$ :YAG welding of refractory metals is impossible to justify.

It may be possible to account for certain of the above parameters and thus improve the fit of the tantalum data by making adjustments to the simulation code. Foremost among these would be to examine the effect of the inverse Bremsstrahlung coefficient on the keyhole depth, a factor that was not explored in this study. In principle, this coefficient can be determined using optical emission data taken during welding [4], though such data are difficult to obtain in practice. In any case, a systematic study of the dependence of the simulated keyhole weld depth on the inverse Bremsstrahlung coefficient should be performed to see if this effect could indeed account for the discrepancy in the tantalum data.

\section{Stainless Steels}

The simulation results for the 304L stainless steel are shown in Fig. 8 and show reasonably close agreement with experiment. At low powers, the model overpredicts slightly, and at high powers, it underpredicts, but as with the vanadium, the trend is accurate, demonstrating the predictive capability of the model for this material. 
The simulation results for the 21-6-9 stainless steel are shown in Fig. 9. Since thermophysical data for this material were unavailable at temperatures other than room temperature [30], the simulations were run with the properties for 304L found in Table 2. We justified this substitution by noting that the room-temperature values that were available matched the corresponding values for 304 stainless steel to within a few percent. Moreover, the steels each contain approximately $70 \mathrm{wt}$. \% Fe, so their respective material properties may be correspondingly similar.

The calculated results for the 21-6-9 steel do not match the experimental data as accurately as they do for the 304L. At $500 \mathrm{~W}$ power, the model predicts the weld depth quite well, but as power is increased, the disparity between simulation and experiment also increases almost linearly. For instance, at $1000 \mathrm{~W}$, the results of the model are only about $70 \%$ of the experimental values, about the same proportional discrepancy as for the tantalum. This trend of decreasing correlation with increasing power is not unique to the 21-6-9; indeed, inspection of the results for the other three materials show a similar tendency, but the effect is much more pronounced in the 21-6-9, whose weld depth increases with laser power at a rate nearly 1.5 times that of the 304L.

Since the material properties of the 21-6-9 steel were assumed to be identical to those for the 304L, there was no difference between the two from the perspective of the simulation. Yet examination of the experimental data for the two steels reveals an appreciable difference between the weld depths in the materials. In an attempt to determine the cause of this discrepancy, we examined the effect that changing the composition of the steel had on the keyhole depth to see if such a variation could result in more accurate prediction of the 21-6-9 behavior.

The simulation has an obvious shortcoming in that it can only accept alloys of binary composition. For the 304L, the two primary constituents were used, with chromium composing 19 percent by weight and iron the remaining fraction. The 21-6-9 steel has approximately the same chromium content by weight, so using this value and having the iron make up the rest would provide no distinction between it and the $304 \mathrm{~L}$ stainless steel. Instead, the secondary constituent was varied from chromium to nickel and manganese, the third and fourth most abundant elements in the alloy by weight, 
respectively. In each case, the secondary constituent weight percent was chosen to be its actual value, with iron composing the balance of the alloy.

The Fe-Ni binary alloy (7.4 wt. \% Ni) was tested first. Among the parameters required by the simulation is the vapor pressure of each alloying element above a liquid composition of that element at the alloy's boiling point. In this case, the boiling point of the alloy was taken to be $3100 \mathrm{~K}$ (the value for pure iron), which is below the boiling point of $\mathrm{Ni}(3168 \mathrm{~K})$, so the vapor pressure of nickel at $3100 \mathrm{~K}(0.67 \mathrm{~atm})$ could be calculated exactly from thermodynamics or by referencing previously tabulated data [31]. A simulation run for $750 \mathrm{~W}$ laser power using the default values listed in Table 2 gave a weld depth $(1.490 \mathrm{~mm})$ negligibly different from the value for the $\mathrm{Fe}-\mathrm{Cr}$ alloy.

The Fe-Mn binary alloy (8.8 wt. \% Mn) was tested next. The 21-6-9 steel contains much more manganese (8.8 wt. \%) than the $304 \mathrm{~L}(1.9 \mathrm{wt} . \%)$, and manganese is known to have a high vapor pressure, which could significantly affect the heat transport at the keyhole edge. However, since the boiling point of manganese $(2334 \mathrm{~K})$ is significantly below that of the alloy, the vapor pressure proved difficult to estimate. Accordingly, the vapor pressure was varied from 2 to $30 \mathrm{~atm}$ to account for possible temperature and pressure fluctuations within the keyhole. Again, simulations were run for $750 \mathrm{~W}$ incident power. As with the Fe-Ni alloy, there was no appreciable change in the calculated weld depth $(1.490 \mathrm{~mm})$ from the value for the Fe-Cr alloy. For further comparison, one simulation at the same power $(750 \mathrm{~W})$ and welding parameters was also run for a sample of $100 \% \mathrm{Mn}$ at $10 \mathrm{~atm}$ vapor pressure. In this sample, the keyhole depth decreased by $0.03 \mathrm{~mm}$, still a tiny margin compared to the difference between the 21-6-9 and 304L experimental data sets.

From these tests, it can be concluded that variations in the alloy composition or elemental vapor pressures have little appreciable effect on the resulting keyhole depth calculations. As a final confirmation of this hypothesis, we returned to the $\mathrm{Fe}-\mathrm{Cr}$ alloy, this time varying the $\mathrm{Cr}$ vapor pressure from $2 \mathrm{~atm}$ to $30 \mathrm{~atm}$, as had been done for the Mn in the Fe-Mn alloy. Again, the simulations were run at $750 \mathrm{~W}$, using the material properties listed in Table 2. The results of these runs are displayed in Fig. 10. The overall contribution to the keyhole depth was still minor, varying the data by only 0.03 $\mathrm{mm}$ over the range of pressures tested. 
A numerical analysis of the evaporative heat flux based on the model used in the simulation reveals that the contribution of this term is at least one order of magnitude below that of both the absorptive and conductive terms. It is therefore reasonable to assume that any differences in the keyhole geometries of the two stainless steels are primarily a consequence of their differing high-temperature thermophysical properties rather than as a direct result of their compositional differences and the evaporative fluxes associated with their elemental constituent vapor pressures. As such data were unavailable for the 21-6-9 stainless steel, this could not be proven.

Before future simulations are performed on the 21-6-9 stainless steel, more accurate high-temperature data for the liquid alloy must be found. In this study, we have used the values for the 304L stainless steel, arguing that the available data at room temperature closely match the data for that alloy. This assumption does not necessarily extend to higher temperatures or to the liquid phase. If such data cannot be obtained, a systematic variation of the primary temperature-dependent physical properties - specific heat, density, electrical resistivity, and thermal conductivity - from their values for the 304L stainless steel might reveal specific dependencies and give some insight into which values might be inaccurate for the high-temperature liquid. It is also possible that the approximation of the boiling point of the alloy is skewing the results, since the model calculations for both the evaporative heat flux and the conducted heat flux at the keyhole wall are dependent upon this value. There is also a secondary effect on the evaporative heat flux, since it depends on the vapor pressures of the alloying elements, which in turn are dependent upon the boiling point of the alloy. An exact value for the boiling point of the steel would eliminate this as a possible source of error. The accuracy of the calculated keyhole depth for the 21-6-9 steel would likely also be improved by modifying the simulation code to accept ternary and quaternary alloys. Such a modification would likely give better results for the more complex alloys such as steels.

\section{Weld Simulations to Investigate Parameter Sensitivity}

The effects of several possible sources of systematic experimental error on the calculated weld depth are also examined. In particular, the beam parameters (size and 
focus) were not measured exactly but rather were estimated using the known parameters of the optics in the experimental setup. In order to examine the effect that a small error in such a parameter might have on the calculated keyhole depth, a series of simulations were run on 304L stainless steel (approximated as an 81 wt. \% Fe, 19 wt. \% Cr binary alloy) using the materials properties in Table 2, but varying the beam focus as well as the beam radius at the output lens and at the focal point.

\section{Beam Radius at Output Lens}

In the first set of runs, the beam radius incident on the sample was fixed at 0.265 $\mathrm{mm}$ and the beam radius at the end of the lens was adjusted from $1 \mathrm{~mm}$ to $50 \mathrm{~mm}$. The beam was assumed to be focused on the sample surface, and the laser power was fixed at $750 \mathrm{~W}$. The results of these simulations are displayed in Fig. 11. Except for very small beam radii ( $\sim 10 \mathrm{~mm}$ at the output lens), the dependence of the keyhole depth on the beam radius is very nearly linear, which is not surprising, considering that variations in this parameter affect power coupling into the keyhole by a similar proportion. The effect is

appreciable: penetration depth decreased from $1.76 \mathrm{~mm}$ for a beam radius of $1 \mathrm{~mm}$ at the output lens to $1.2 \mathrm{~mm}$ for a beam radius of $50 \mathrm{~mm}$ at the output lens. However, the likelihood of the beam radius estimate being off by as much as $20-25 \mathrm{~mm}$ on either side is extremely small (the value used in previous simulations was $25 \mathrm{~mm}$ ).

\section{Spot Size}

In the second set of runs, the beam radius at the end of the lens was fixed at 25 $\mathrm{mm}$ and the beam radius incident on the sample was adjusted from $0.05 \mathrm{~mm}$ to $0.5 \mathrm{~mm}$. As before, the laser power was fixed at $750 \mathrm{~W}$, and no beam defocusing was assumed. The results of these simulations are given in Fig. 12. Beyond a radius of $\sim 0.3 \mathrm{~mm}$, the penetration depth decreases as the beam radius at the focus is increased, since the local intensity of the beam decreases proportionately. Qualitatively, this trend matches that in Fig. 11, except that the dependence of the weld depth on minor changes in the beam radius is even more apparent. However, there is an anomalous increase in weld 
penetration $(1.35 \mathrm{~mm}$ to $1.61 \mathrm{~mm})$ as the beam radius increases from $0.5 \mathrm{~mm}$ to $1.0 \mathrm{~mm}$. This is likely due to the fact that for a sharper focus, there is faster divergence below the material surface, so the local intensity of the beam decreases more rapidly with the weld depth, otherwise dampening the effect of the high power density at the surface.

Focus

For the third set of simulations, the beam radii at the end of the lens and incident on the sample were fixed at the default values and the beam focus was varied from -1.5 $\mathrm{mm}$ to $+1.5 \mathrm{~mm}$, with respect to the sample surface. This series of simulations tests the sensitivity of the weld penetration to possible errors in setting the beam focus. Results for simulations run on a sample of $304 \mathrm{~L}$ stainless steel at $750 \mathrm{~W}$ laser power are shown in Fig. 13. For positive beam defocusing (focus above the surface), the dependence of the keyhole depth is approximately linear, since the power coupling scales with the crosssectional area of the beam. However, for negative defocusing (focus below the surface), the penetration begins to decrease as the beam is defocused beyond $1 \mathrm{~mm}$ below the surface.

It can be seen from Figs. 11, 12, and 13 that adjustment of the beam parameters can have a significant impact on the total keyhole penetration. In practice, the actual values of these parameters do not differ as significantly as the values used in the simulations, so the effect of any systematic error owing to uncertainty in these factors is likely quite small. However, these data do indicate the relative importance of the absorptive heat flux term in the calculation of weld geometry, since the beam parameters ultimately enter into this term.

\section{Absorptivity}

Accordingly, we chose to examine another absorption effect by varying the material absorptivity (Fresnel absorption coefficient). Since this parameter is wavelength dependent, an additional set of runs was performed to compare the keyhole depths at various powers for the $\mathrm{Nd}$ :YAG laser with those calculated for a $\mathrm{CO}_{2}$ laser. The results 
of these simulations on a sample of 304L stainless steel, using the materials properties listed in Table 2, are plotted in Fig. 14. Metals are highly reflective to radiation at the $\mathrm{CO}_{2}$ laser wavelength $(10.6 \mu \mathrm{m})$. Therefore, weld depths are 2 to 3 times shallower for this wavelength than for a Nd:YAG laser operating at a similar power. This plot confirms the strong dependence of the weld depth on the absorption flux term in the model. It is therefore likely that any significant error in the simulated values of any of the four materials is due to the one of the factors in the heat flux due to optical absorption (Eq. 7), as this term seems to have the largest numerical effect on the calculated weld depth.

We conclude our discussion with a comparison of the overall laser power absorbed as calculated by the simulation for the tantalum, vanadium, and 304L stainless steel samples. These are plotted against incident laser power in Fig. 15. The trends expressed in this plot prove to be reasonable predictors of the resulting keyhole depth: the steel absorbs the most incident power on average, followed by the vanadium, and then the tantalum. A further investigation into the physical significance of the peaks in absorbed power fraction for the three materials might prove interesting, as we can provide no explanation for this phenomenon at this time.

\section{Conclusions}

1. A laser keyhole weld model was tested for various materials (304L stainless steel, V, Ta, and 21-6-9 stainless steel) at various incident laser powers, and the resulting keyhole penetrations were compared with experimental weld depths.

2. Results for the 304L stainless steel demonstrate the predictive power of the simulation for that material. The calculated keyhole depth matched the experimental value to within $10 \%$ at most powers, and the nearly linear scaling of the keyhole depth with incident laser power is correctly predicted. 
3. Results for the vanadium could likewise be used for reliable weld geometry prediction. The calculated keyhole depth matched the experimental value to within 10$15 \%$ at all powers.

4. Results for the 21-6-9 stainless steel were less accurate, with the simulation data differing by almost $30 \%$ from the experimental data. The discrepancy between simulation and experiment is likely due to a divergence of the thermophysical properties of 21-6-9 and 304L at high temperatures. Since accurate material properties for the 21-69 stainless steel were unavailable, the materials properties of the 304 steel were used instead.

5. Results for the tantalum were the least accurate of the metals tested, with the simulation data differing by more than $30 \%$ from the experimental data. This discrepancy can be initially attributed to the boiling point of tantalum, irregular or varying plasma interactions in the vapor cavity, density of tantalum, or the angle of incidence of the laser.

6. Changes in alloy composition alone have little effect on the calculated weld geometry, in part because the model only accepts binary alloy compositions.

7. Of the three major contributions to heat flux accounted for in the model-conduction at the keyhole wall, optical absorption by the material, and evaporation at the walloptical absorption proved to be the most significant in determining weld depth. Errors in weld depth calculation for the materials tested are likely related to this term. The predictive power of the model might be increased upon further investigation of the factors contributing to the total optical absorption.

\section{Future Work}

Future investigations should begin with modifications to the simulation to allow for multi-component alloys and off-normal laser beam incidence. The modified code 
could be tested first with more common elements and alloys for which exact hightemperature thermophysical data are available. There are few references available for less commonly used metals such as vanadium and tantalum, but data for the more common alloy systems are easily accessible. These results could then be experimentally verified, much as we have done here, as a test of the universality of the model. In addition, when future welds are performed, a measurement of the optical emission spectrum during welding would allow for an accurate determination of the inverse Bremsstrahlung absorption coefficient, a factor that was not thoroughly investigated in this study owing to its difficulty to compute without such a spectrum. The beam parameters should also be measured rather than estimated or calculated, to ensure that no additional error is introduced into the experiment as a result.

\section{Acknowledgments}

The authors would like to thank Bill Bish for his helpful suggestions and support, as well as H. Zhao and Prof. T. DebRoy of the Pennsylvania State University for providing the simulation code. This work was performed under the auspices of the U.S. Department of Energy, University of California Lawrence Livermore National Laboratory, under contract W-7405-Eng-48. 


\section{References}

1) Palmer, T.A., B.C. Wood, J.W. Elmer, C. Westrich, et al., Characterization of Stainless Steel and Refractory Metal Welds Made Using a Diode-Pumped, Continuous Wave Nd:YAG Laser (UCRL-ID-146005).

2) Zhao, H. and T. DebRoy, A Computer Program for the Calculation of Keyhole Geometry and Temperature Field during High Energy Density Beam Welding (Unpublished research, 2002).

3) Ready, J.F., ed., Laser Institute of America Handbook of Laser Materials Processing (Laser Institute of America and Magnolia Publishing, Inc., 2001).

4) Bramson, M.A., Infrared Radiation: A Handbook for Applications (Plenum, New York, 1968).

5) DebRoy, T. and S.A. David, Rev. Mod. Phys., 1995, 67 (1), 85-112.

6) ZelDovich, Y.B., and Y.P. Raizer, Physics of Shock Waves and High Temperature Hydrodynamic Phenomena (Academic, New York, 1966).

7) Collur, M.M., A. Paul, and T. DebRoy, Metall. Trans. B, 1987, 18B, 733-740.

8) Sahoo, P., M.M. Collur, and T. DebRoy, Metall. Trans. B, 1988, 19B, 967-972.

9) Zhao, H., D.R. White, and T. DebRoy, Inter. Mater. Rev., 1999, 44 (6), 238-266.

10) Zhao, H. and T. DebRoy, Metall. Trans. B, 2001, 32B (1), 163-172.

11) Lide, D.R., ed., CRC Handbook of Chemistry and Physics, $81^{\text {st }}$ ed. (CRC Press, FL, 2000).

12) Gerritsen, A.N., "Metallic Conductivity, Experimental Part” in: S. Flügge (ed.), Handbuch der Physik, Vol. 19 (Springer-Verlag, Berlin, 1956).

13) Kaye, G.W.C. and T.H. Laby, Tables of Physical and Chemical Constants (Longman, London, 1995).

14) Yaws, C.L., Handbook of Thermal Conductivity (Gulf Publishing, Houston, 1997).

15) Ho, C.Y. and Y.S. Touloukian, Purdue University Thermophysical Properties Research Center, TPRC Data Series, Thermophysical Properties of Matter: Thermal Conductivity (IFI, Plenum, New York, 1977).

16) Ho, C.Y., P.E. Liley, and R.W. Powell, National Bureau of Standards, National Standard Reference Data Series, No. 16: Thermal Conductivity of Selected Materials, Pt. 2 (USGPO, Washington, D. C., 1968).

17) Mills, K.C., Recommended Values of Thermophysical Properties for Selected Commercial Alloys (ASM, Materials Park, OH, 2002).

18) Ho, C.Y. and Y.S. Touloukian, Purdue University Thermophysical Properties Research Center, TPRC Data Series, Thermophysical Properties of Matter: Specific Heat (IFI, Plenum, New York, 1977).

19) James, A. and M. Lord, VNR Index of Chemical and Physical Data (Van Nostrand Reinhold, New York, 1992).

20) Chase, M.W., National Institute of Standards and Technology, NIST-JANAF Thermochemical Tables, $4^{\text {th }}$ ed., taken from J. Phys. Chem. Ref. Data, Monograph 9 (American Institute of Physics, NY, 1998).

21) Filing Code: SS-254, "AISI 304 \& 304L" (May 1971), Alloy Digest (ASM, Materials Park, OH, 2000).

22) Gmelins Handbuch der Anorganischen Chemie: Vanadium, 48, A2 (Verlag Chemie, Weinheim, 1968), 454-6. 
23) Gmelins Handbuch der Anorganischen Chemie: Tantal, 50, A2 (Verlag Chemie, Weinheim, 1969), 386-7.

24) Grigoriev, I.S. and E.Z. Meilikhov, Handbook of Physical Quantities (CRC Press, FL, 1997).

25) Zinovev, V.E., Handbook of Thermophysical Properties of Metals at High Temperatures (Nova, New York, 1996).

26) Peckner, D. and I.M. Bernstein, Handbook of Stainless Steels (McGraw-Hill, New York, 1977).

27) Meaden, G.T., Electrical Resistance of Metals (Plenum, New York, 1965).

28) Pitscheneder, W., Contributions to the Understanding and Optimization of Laser Surface Alloying, Doctoral Thesis, Department of Physical Metallurgy and Materials Testing, University of Leoben, Austria (2001), pp. 1-242.

29) Nonhof, C.J., Material Processing with Nd-Lasers (Electrochemical Publications Limited, Scotland, 1988).

30) Filing Code: SS-327, “Armco Nitronic 40" (May 1976, revised August 1990), Alloy Digest (ASM, Materials Park, OH, 2000).

31) Barin, I. and O. Knacke, Thermochemical Properties of Inorganic Substances (Verlag Stahleisen MBH, New York, 1973). 
Table 1: Some keyhole-geometry weld depths and welding parameters for the welds described in [1].

\begin{tabular}{|c|c|c|c|c|c|}
\hline Material & Power (W) & Shielding Gas & $\begin{array}{l}\text { Travel Speed } \\
\text { (in/min) }\end{array}$ & $\begin{array}{c}\text { Incident Angle } \\
\text { (deg) }\end{array}$ & $\begin{array}{l}\text { Weld Depth } \\
(\mathrm{mm})\end{array}$ \\
\hline \multirow[t]{4}{*}{ 304L SS } & \multicolumn{2}{|c|}{$500 \mathrm{He} @ 90$ cfh } & 45 & 0 & 0.83 \\
\hline & \multicolumn{2}{|c|}{ 750He @ 90 cfh } & 45 & 0 & 1.54 \\
\hline & \multicolumn{2}{|c|}{ 1000He@90 cfh } & 45 & 0 & 2.05 \\
\hline & \multicolumn{2}{|c|}{ 1250He@90 cfh } & 45 & 0 & 2.43 \\
\hline \multirow{4}{*}{ 21-6-9 SS } & \multirow{2}{*}{\multicolumn{2}{|c|}{\begin{tabular}{l|l}
$500 @ 90$ cfh \\
\end{tabular}}} & & & \\
\hline & & & 45 & 0 & 1.00 \\
\hline & \multicolumn{2}{|c|}{\begin{tabular}{l|l}
750 & $\mathrm{He} 90$ cfh \\
\end{tabular}} & 45 & 0 & 1.92 \\
\hline & \multicolumn{2}{|c|}{ 1000He@90 cfh } & 45 & 0 & 2.66 \\
\hline \multirow{5}{*}{ Vanadium } & \multicolumn{2}{|c|}{ 1000He @ 90 cfh } & 45 & 10 & 1.17 \\
\hline & \multicolumn{2}{|c|}{ 1250He@90 cfh } & 45 & 10 & 1.47 \\
\hline & \multicolumn{2}{|c|}{ 1500 He @ 90 cfh } & 45 & 10 & 1.87 \\
\hline & \multicolumn{2}{|c|}{ 1750He@90 cfh } & 45 & 10 & 2.21 \\
\hline & \multicolumn{2}{|c|}{ 2000/He@90 cfh } & 45 & 10 & 2.48 \\
\hline \multirow{3}{*}{ Tantalum } & \multicolumn{2}{|c|}{ 1500He @ 150 cfh } & 30 & 10 & 1.58 \\
\hline & \multicolumn{2}{|c|}{ 1750|He @ 150 cfh } & 30 & $\frac{10}{10}$ & $\begin{array}{l}1.50 \\
1.78\end{array}$ \\
\hline & \multicolumn{2}{|c|}{ 2000|He@ @ 150 cfh } & 30 & 10 & 2.20 \\
\hline
\end{tabular}


Table 2: Vanadium, tantalum, 21-6-9 SS, and 304L SS materials properties required as input into the Penn State simulation.

\begin{tabular}{|c|c|c|c|c|}
\hline Material Property & Vanadium & Tantalum & \multicolumn{2}{|c|}{304 Stainless Steel } \\
\hline Boiling Point (K) [11] & 3680 & 5731 & \multicolumn{2}{|c|}{$3100^{a}$} \\
\hline $\begin{array}{l}\text { Thermal Conductivity } \\
\left(\mathbf{W} / \mathbf{m}^{*} \mathbf{K}\right)^{\mathbf{b}}[12-17]\end{array}$ & 50 & 67 & \multicolumn{2}{|c|}{29} \\
\hline $\begin{array}{l}\text { Specific Heat }\left(\mathbf{J} / \mathbf{k g}^{\star} \mathbf{K}\right)^{\mathbf{b}} \\
{[17-20]}\end{array}$ & 907 & 231 & \multicolumn{2}{|c|}{800} \\
\hline Density $\left(\mathrm{kg} / \mathrm{m}^{\wedge} 3\right)^{\mathbf{b}}[11,17]$ & 5500 & 15000 & \multicolumn{2}{|c|}{5800} \\
\hline $\begin{array}{l}\text { Solidus Temp./ Melting } \\
\text { Point (K) }[11,21]\end{array}$ & 2183 & 3290 & \multicolumn{2}{|c|}{1673} \\
\hline $\begin{array}{l}\text { Electrical Resistivity } \\
\left(\mu \Omega^{*} \mathbf{c m}\right)^{\mathrm{b}}[13,22-27]\end{array}$ & 156.6 & 130.0 & \multicolumn{2}{|c|}{143.5} \\
\hline $\begin{array}{l}\text { Fresnel Absorption } \\
\text { Coeff. (unitless) }^{c}\end{array}$ & 0.355 & 0.330 & \multicolumn{2}{|c|}{0.340} \\
\hline $\begin{array}{l}\text { Bremstrahlung } \\
\text { Absorption Coeff. }\left(m^{-1}\right)^{d}\end{array}$ & 100 & 100 & \multicolumn{2}{|c|}{100} \\
\hline $\begin{array}{l}\text { Binary Alloy } \\
\text { Composition (wt\%) }\end{array}$ & $\mathrm{N} / \mathrm{A}$ & $\mathrm{N} / \mathrm{A}$ & $81 \% \mathrm{Fe}$ & $19 \% \mathrm{Cr}$ \\
\hline Atomic Weight (amu) [11] & 50.94 & 180.95 & 56 & 19 \\
\hline $\begin{array}{l}\text { Vapor Pressure at } \\
\text { Boiling Point (atm) }\end{array}$ & 1 & 1 & $1^{\mathrm{e}}$ & $2^{\mathrm{e}}$ \\
\hline $\begin{array}{l}\text { Heat of Vaporization } \\
\text { (MJ/kg) [11] }\end{array}$ & 8.87 & 4.1 & 6.52 & 6.21 \\
\hline
\end{tabular}

a) taken to be the boiling point of iron

b) for the liquid metal at the boiling point

c) calculated from the electrical resistivity of the liquid at the boiling point using Eq. 6

d) estimated based on a typical value for $\mathrm{CO}_{2}$ welding of aluminum alloys

e) for the steel, the iron vapor pressure is $1 \mathrm{~atm}$ since the boiling point has been estimated as the boiling point of iron, and the chromium vapor pressure is estimated at $2 \mathrm{~atm}$ since its elemental boiling point is below that of the alloy 
Table 3: A comparison of calculated keyhole depth and experimental weld depth as a function of incident laser power for each of the welding materials. The calculated absorbed power is also tabulated.

\begin{tabular}{|c|c|c|c|c|}
\hline Material & $\begin{array}{l}\text { Incident } \\
\text { power (W) }\end{array}$ & $\begin{array}{l}\text { Weld depth } \\
\text { (experimental) }\end{array}$ & $\begin{array}{l}\text { Keyhole depth } \\
\text { (simulation) }\end{array}$ & $\begin{array}{l}\text { Absorbed power } \\
\text { (simulation) }\end{array}$ \\
\hline \multirow[t]{4}{*}{304 L SS } & 500 & 0.83 & 0.96 & 0.550 \\
\hline & 750 & 1.54 & 1.49 & 0.596 \\
\hline & 1000 & 2.05 & 1.92 & 0.595 \\
\hline & 1250 & 2.43 & 2.28 & 0.585 \\
\hline \multirow{3}{*}{$21-6-9$ SS } & 500 & 100 & 0.96 & 0550 \\
\hline & 750 & 1.92 & 1.49 & 0.596 \\
\hline & 1000 & 2.66 & 1.92 & 0.595 \\
\hline \multirow[t]{5}{*}{ Vanadium } & 1000 & 1.17 & 1.11 & 0.613 \\
\hline & 1250 & 1.47 & 1.41 & 0.624 \\
\hline & 1500 & 1.87 & 1.69 & 0.628 \\
\hline & 1750 & 2.21 & 1.93 & 0.617 \\
\hline & 2000 & 2.48 & 2.15 & 0.604 \\
\hline \multirow{3}{*}{ Tantalum } & 1500 & 158 & 1.13 & 0.586 \\
\hline & 1750 & 1.78 & 1.34 & 0.600 \\
\hline & 2000 & 2.20 & 1.52 & 0.599 \\
\hline
\end{tabular}




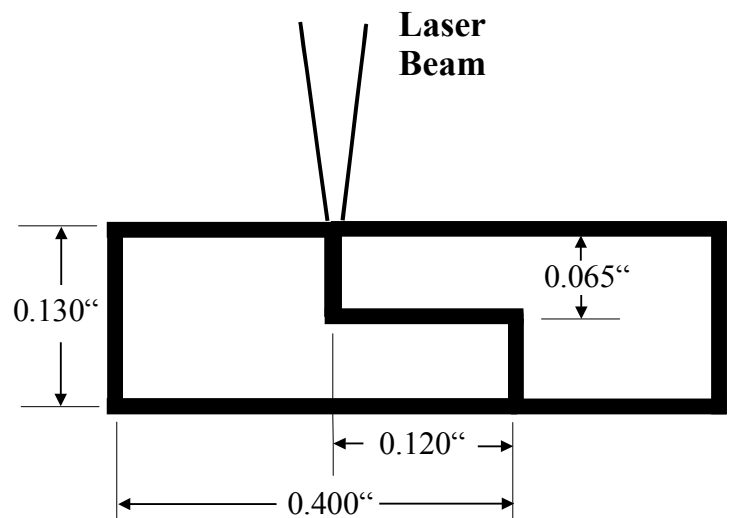

(a)

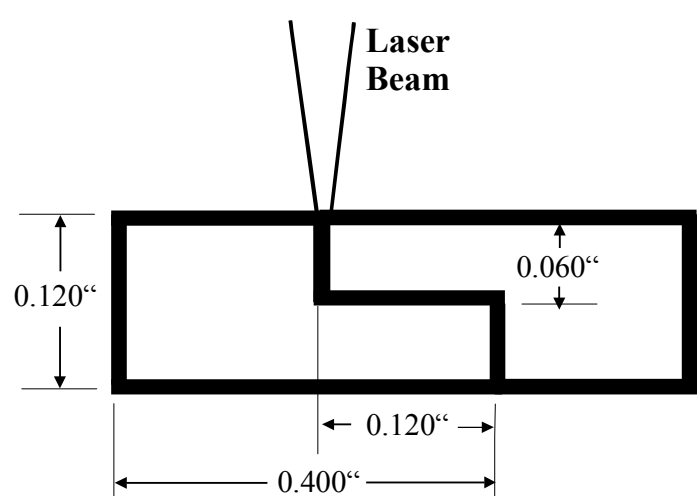

(b)

Figure 1: Schematic diagrams of the sample geometry cross-section for the (a) tantalum samples and (b) stainless steel and vanadium samples. 


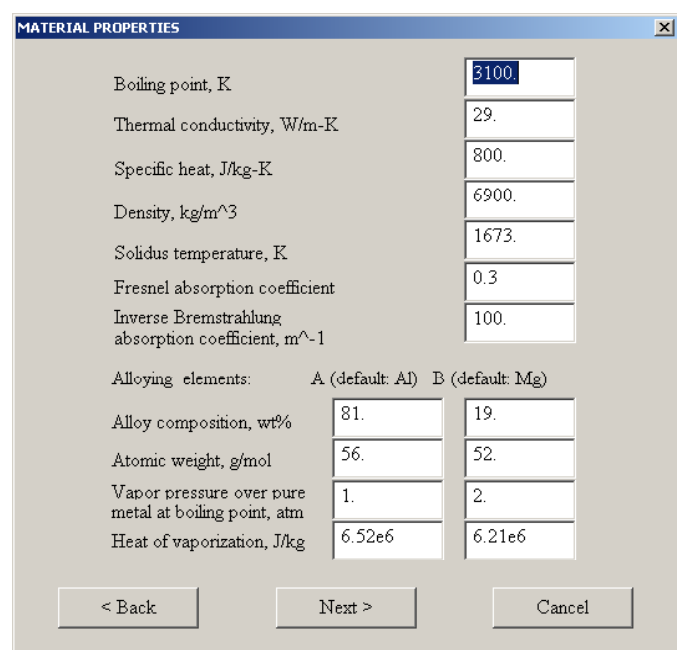

(a)

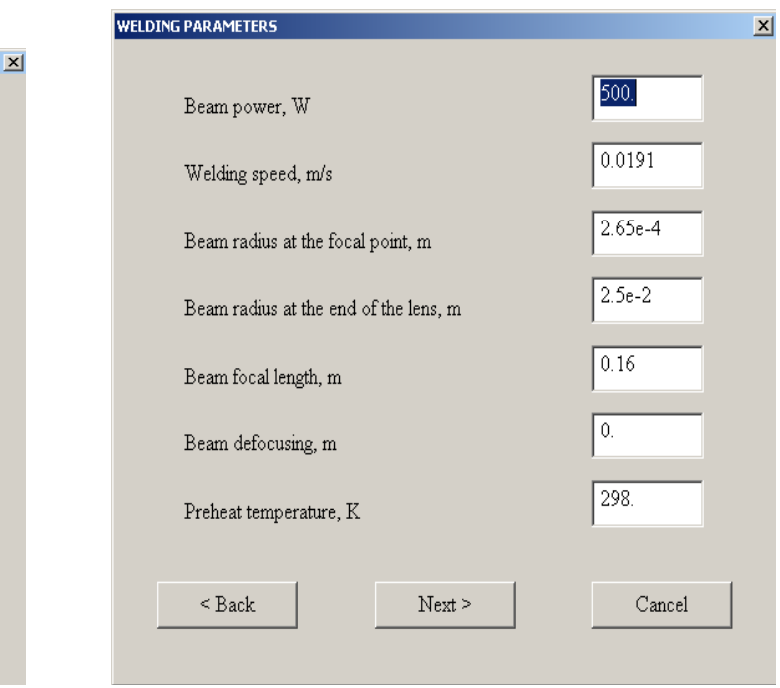

(b)

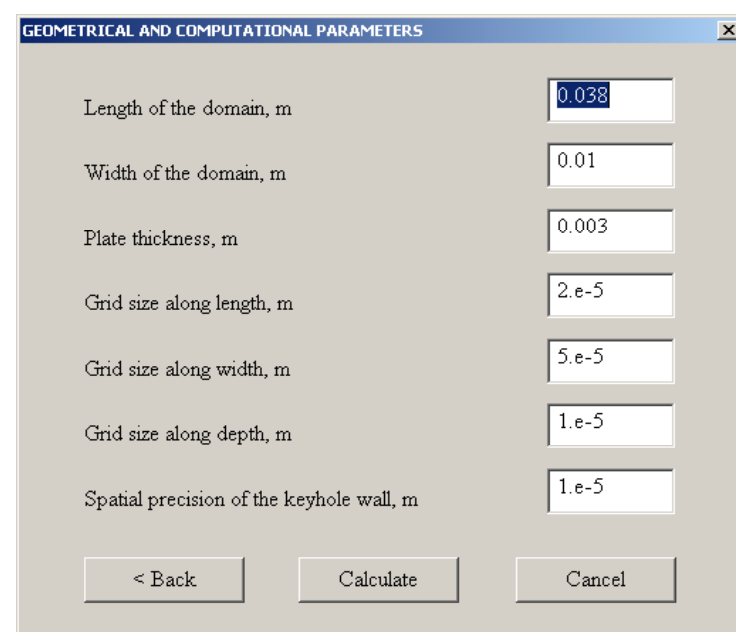

(c)

Figure 2: Screenshots of the simulation, showing the input parameters required by the simulation. Inputs are divided into screens prompting for (a) the material properties, (b) the welding parameters, and (c) the geometrical and computational parameters. 


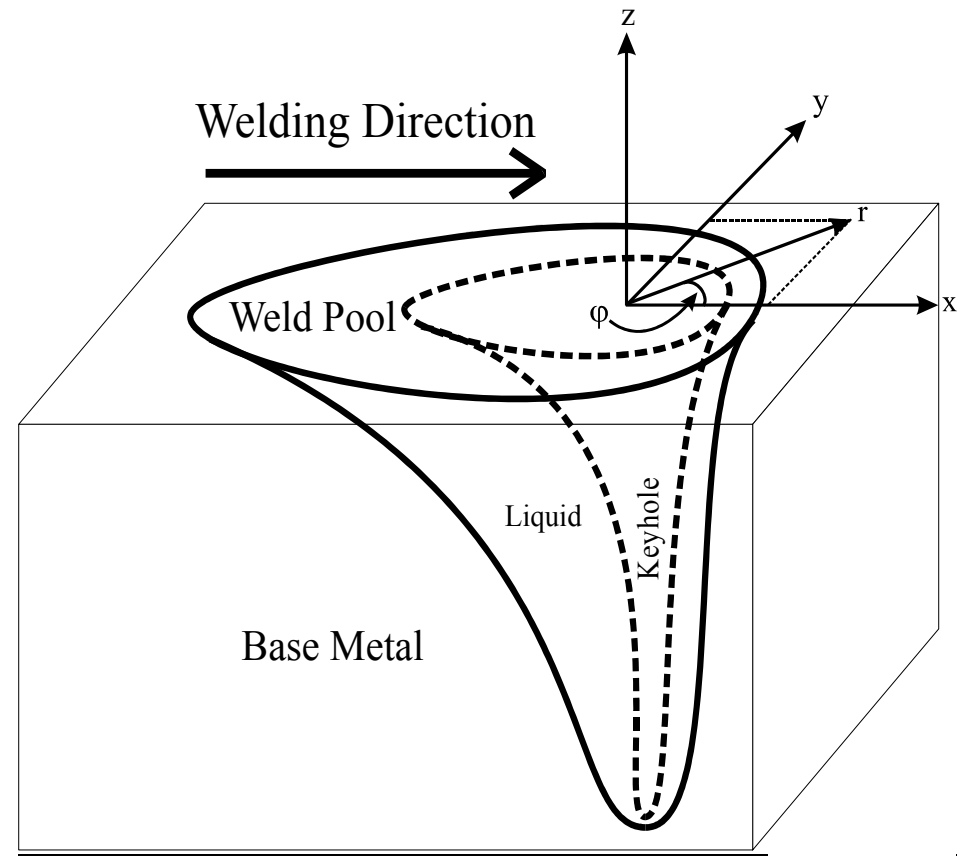

(a)

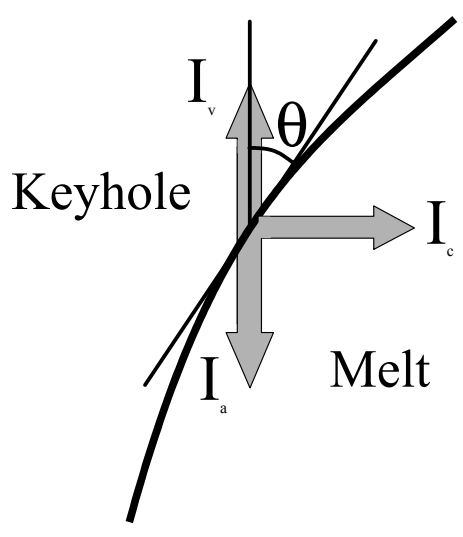

(b)

Figure 3: Schematic diagram of weld model. The cylindrical coordinate system is illustrated in (a), and (b) shows the directions of the three major heat flux contributors at the keyhole wall. $I_{c}, I_{a}$, and $I_{v}$ designate the contributions due to heat conduction, optical absorption, and evaporation, respectively.

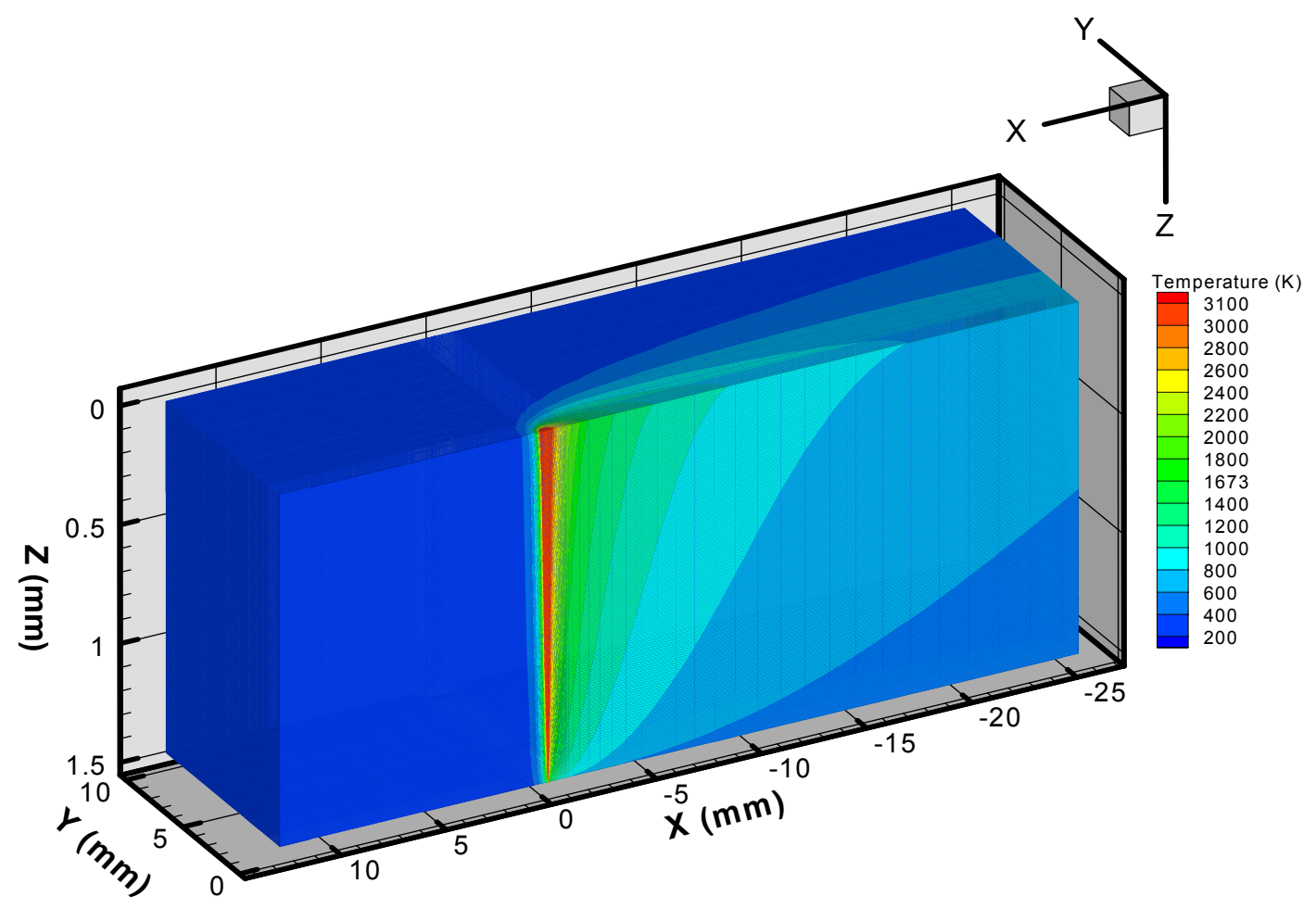

Figure 4: Temperature field of a $750 \mathrm{~W}$ keyhole weld on 304L stainless steel, using the default materials properties listed in Table 2 . The $3100 \mathrm{~K}$ contour near $\mathrm{x}=0$ represents the edge of the keyhole wall. 


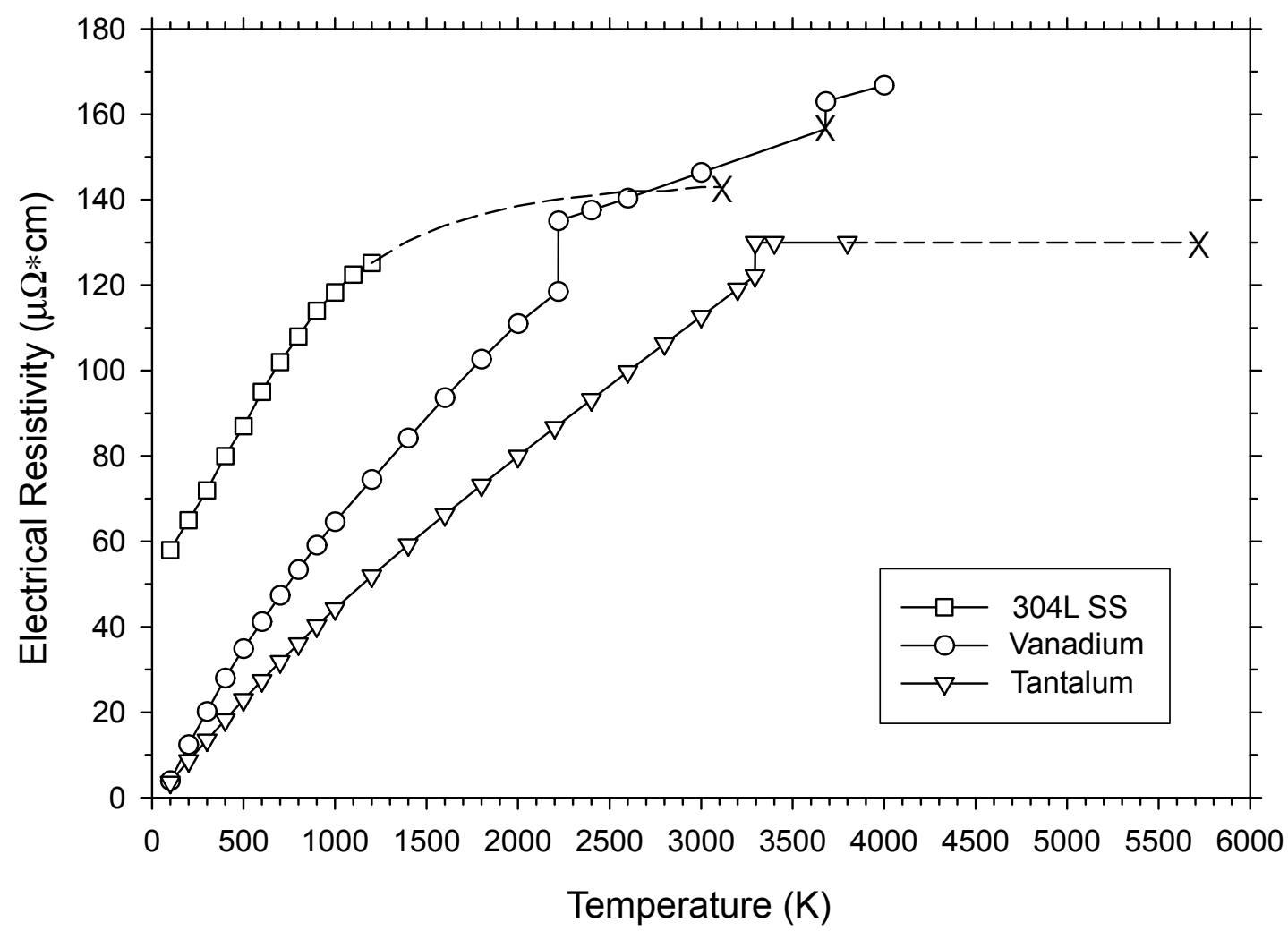

Figure 5: Resistivities of vanadium, tantalum, and 304L stainless steel as a function of temperature. Values for vanadium and tantalum have been corrected to account for volumetric thermal expansion. Sudden increases in resistivity occur at phase transition temperatures. A dotted line indicates extrapolated data, and the "X" on each plot indicates the value of resistivity used in the absorptivity calculation (the value for the liquid at the boiling point). [13,24-26] 


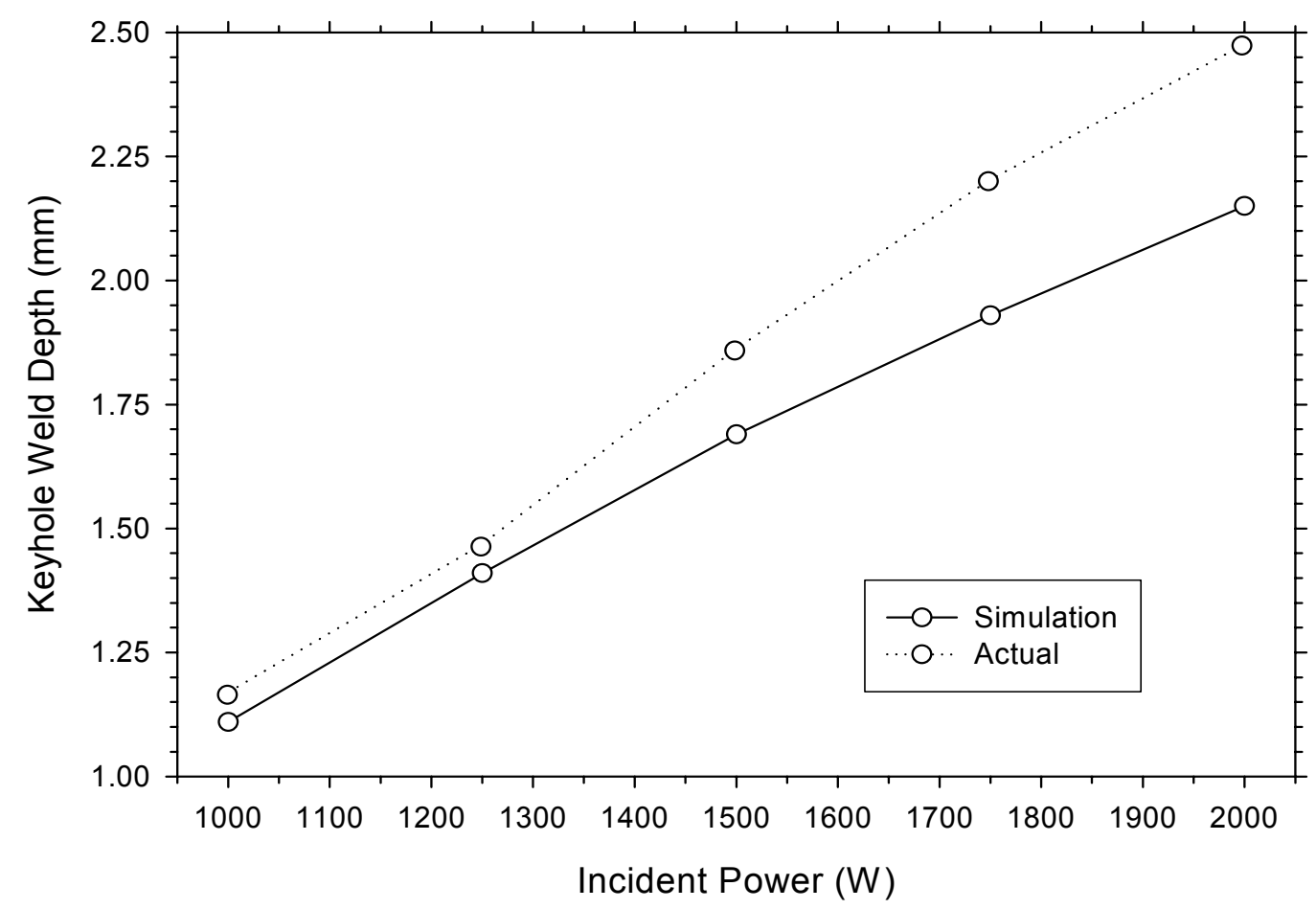

Figure 6: Keyhole penetration as a function of incident laser power for vanadium. Simulated and experimental results are plotted for side-by-side comparison.

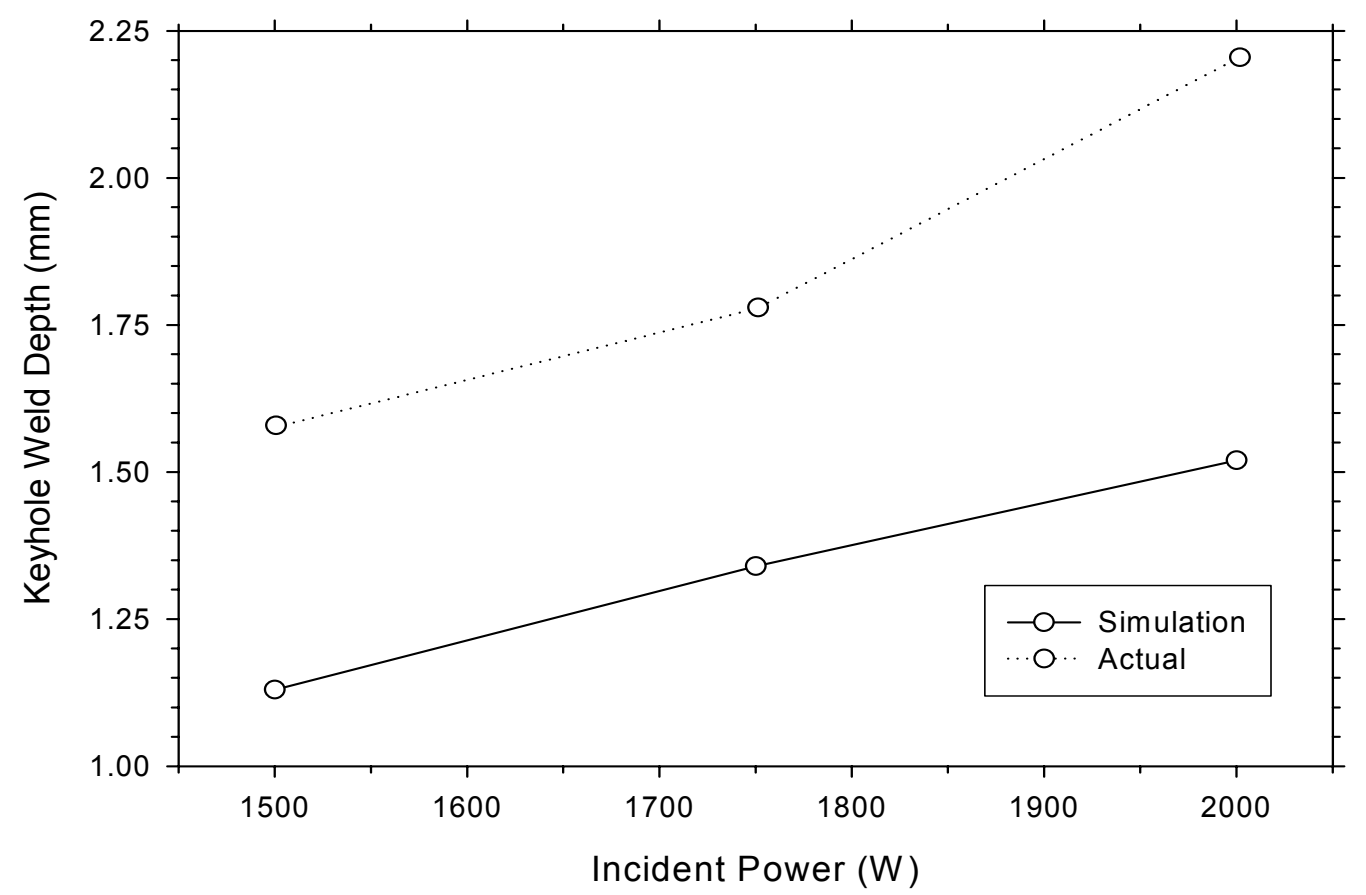

Figure 7: Keyhole penetration as a function of incident laser power for tantalum. Simulated and experimental results are plotted for side-by-side comparison. 


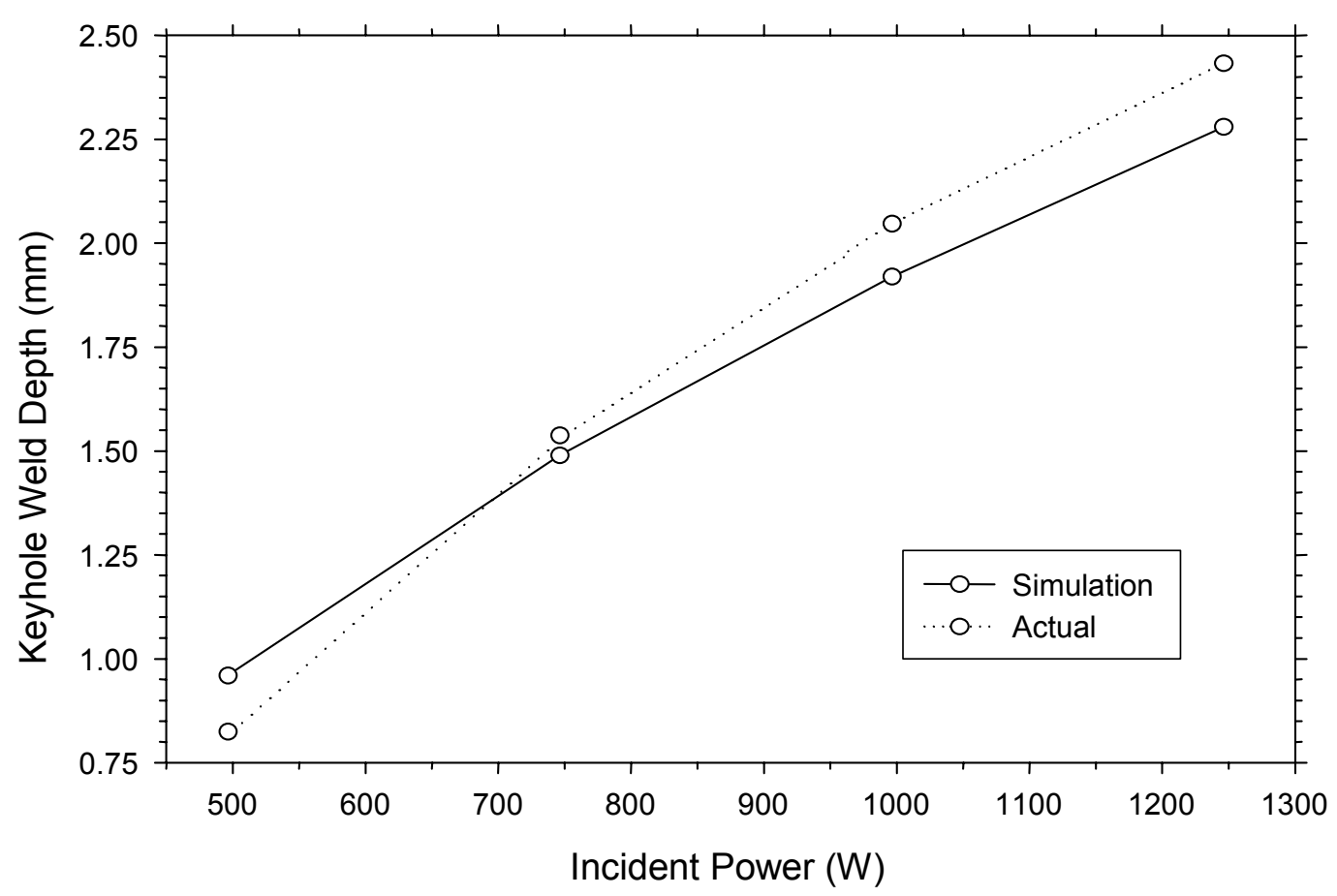

Figure 8: Keyhole penetration as a function of incident laser power for 304L stainless steel. Simulated and experimental results are plotted for side-by-side comparison.

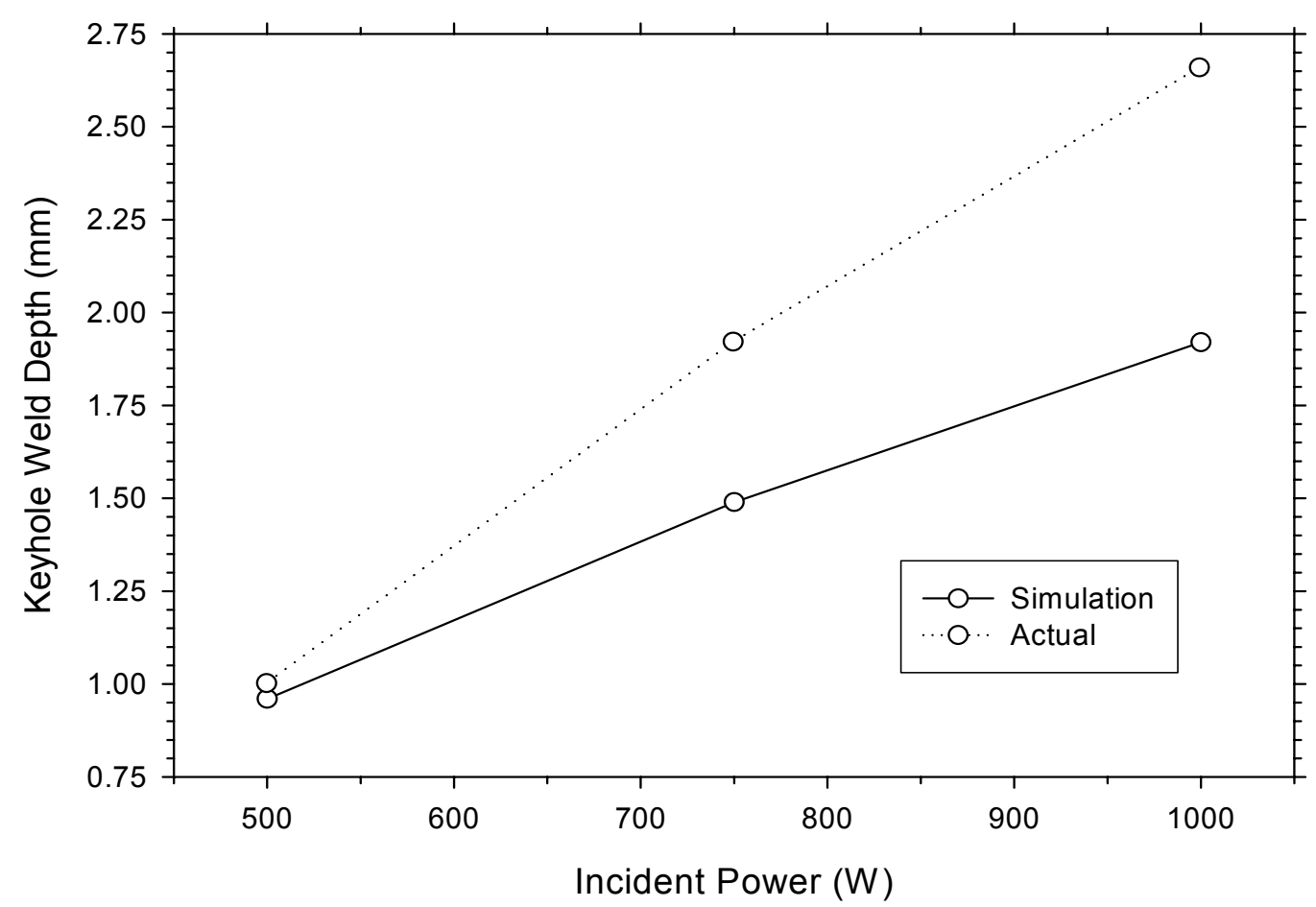

Figure 9: Keyhole penetration as a function of incident laser power for 21-6-9 stainless steel. Simulated and experimental results are plotted for side-by-side comparison. 


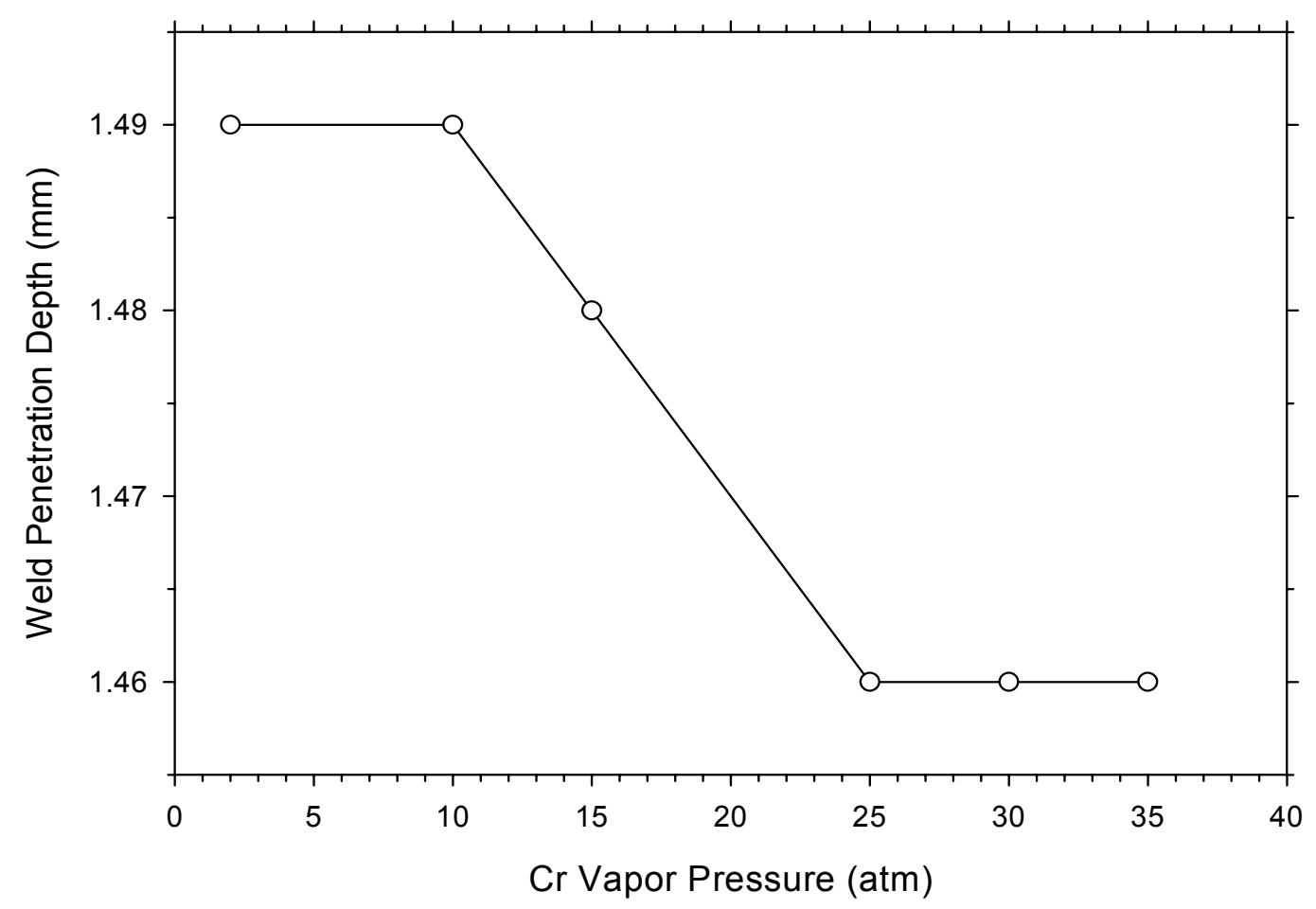

Figure 10: Calculated keyhole penetration as a function of chromium vapor pressure for $304 \mathrm{~L} \mathrm{SS}$ at $750 \mathrm{~W}$ incident power. Other material parameters are the default values listed in Table 2.

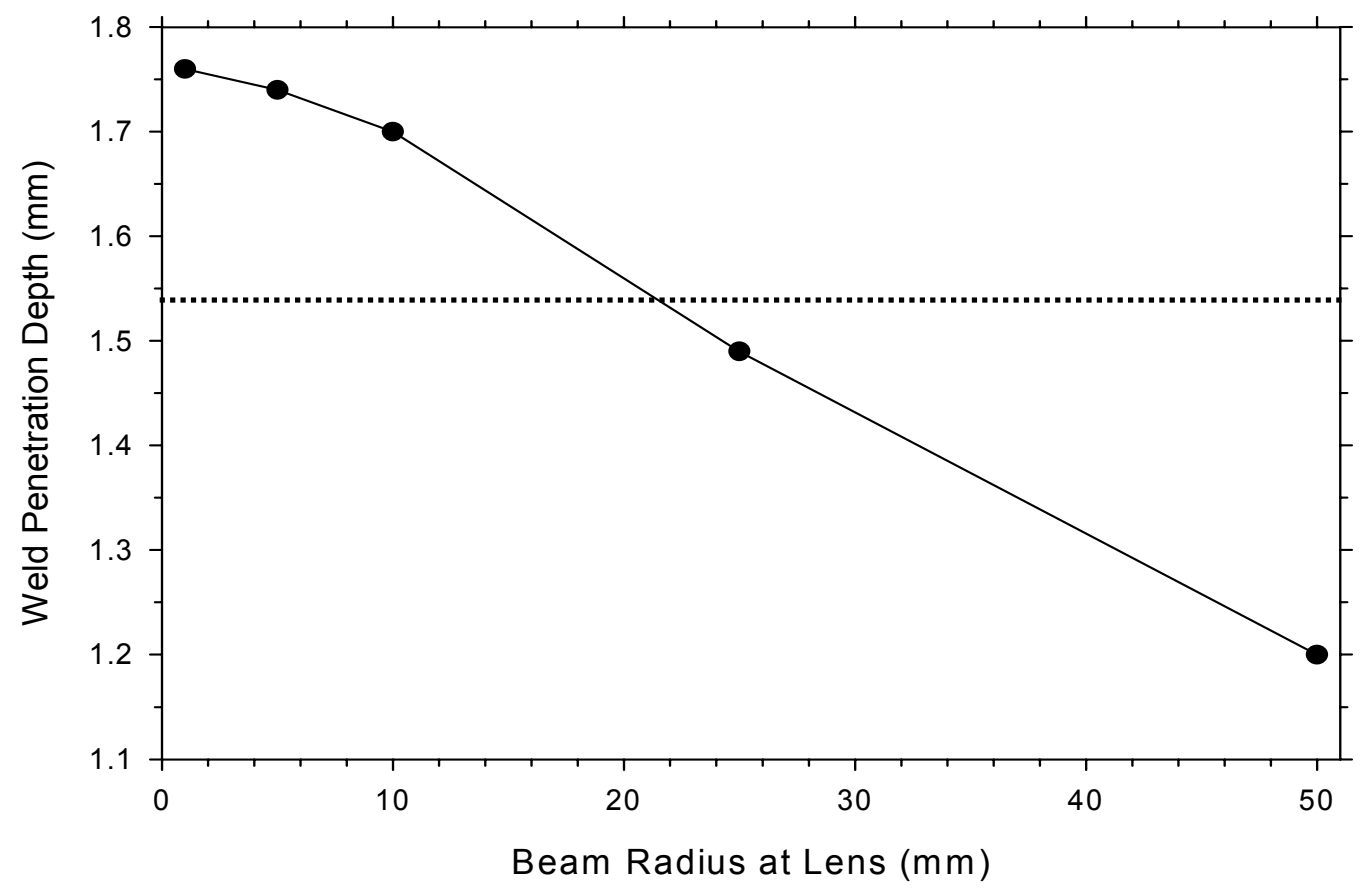

Figure 11: Calculated keyhole penetration as a function of laser beam radius at the output lens for 304L SS at $750 \mathrm{~W}$ incident power. Other material parameters are the default values listed in Table 2 . The dotted line indicates the experimental weld depth. 


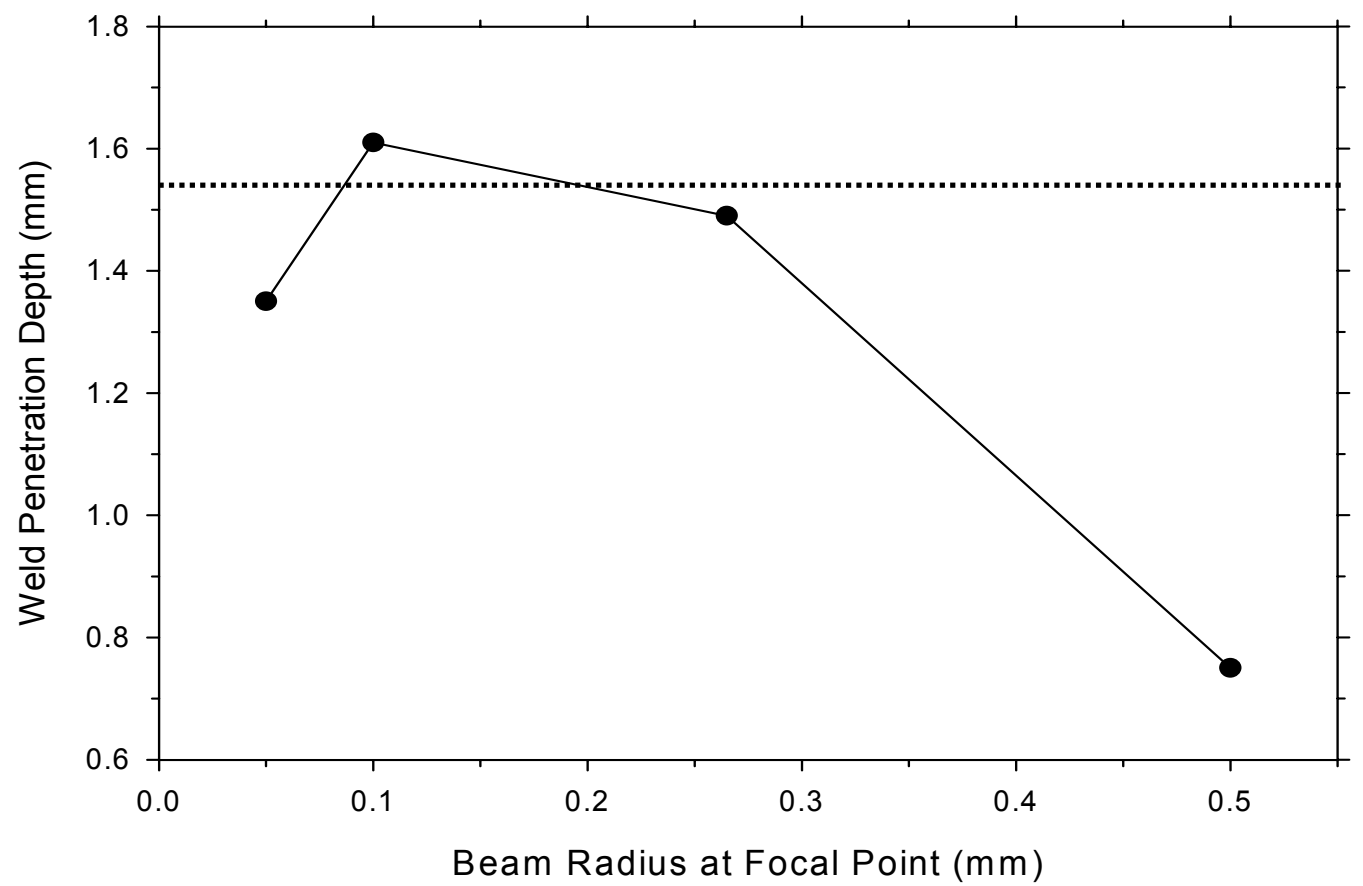

Figure 12: Calculated keyhole penetration as a function of laser beam radius at the focal point for 304L SS at $750 \mathrm{~W}$ incident power. Other material parameters are the default values listed in Table 2 . The dotted line indicates the experimental weld depth.

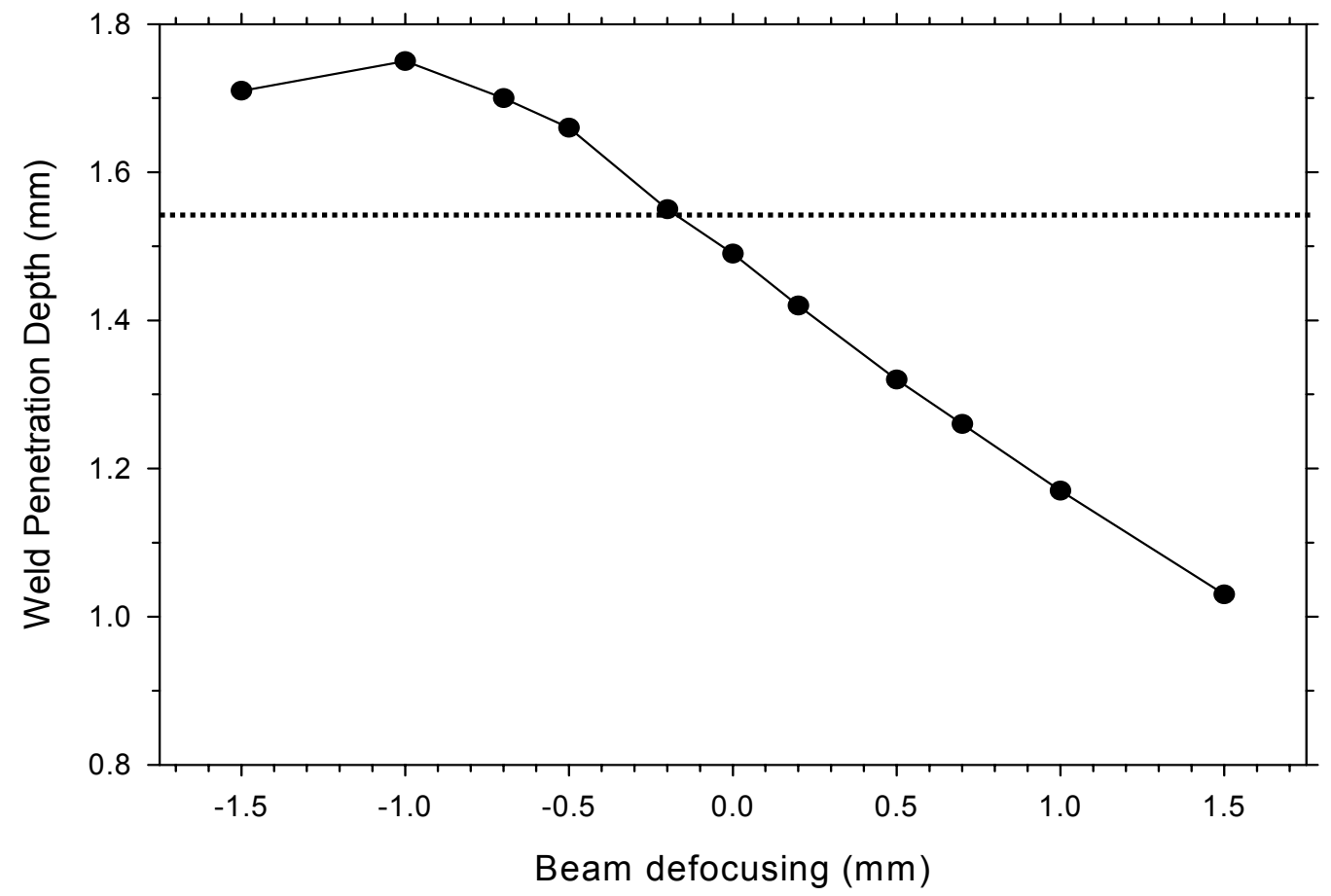

Figure 13: Calculated keyhole penetration as a function of laser beam defocusing for $304 \mathrm{~L} \mathrm{SS}$ at $750 \mathrm{~W}$ incident power. Other material parameters are the default values listed in Table 2. The dotted line indicates the experimental weld depth. 


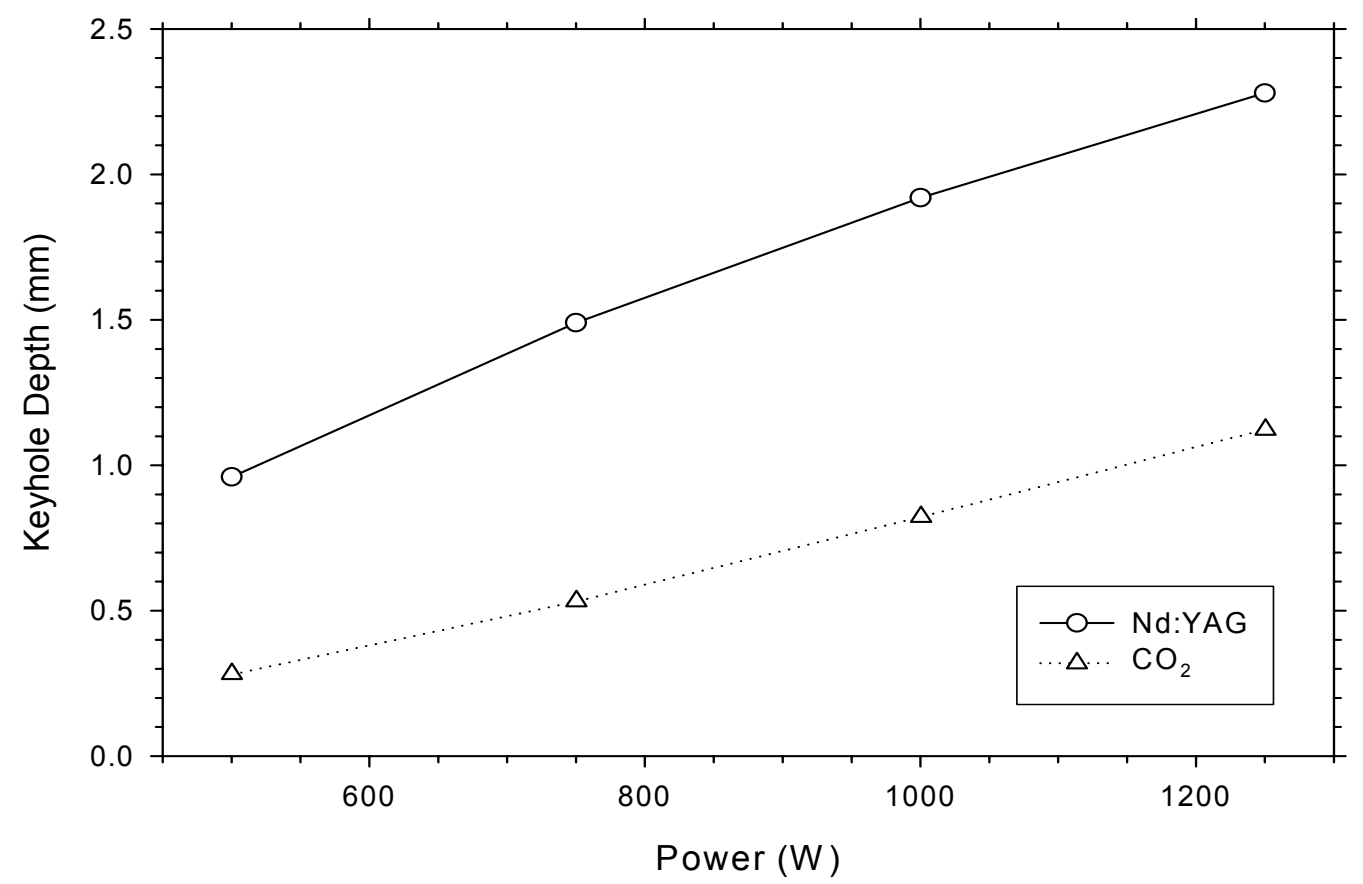

Figure 14: A comparison of calculated keyhole penetration depth as a function of power for Nd:YAG $(\lambda=1.064 \mu \mathrm{m}$; absorptivity $=0.34)$ and $\mathrm{CO}_{2}(\lambda=10.6 \mu \mathrm{m}$; absorptivity $=$ 0.13 ) laser welders, demonstrating the absorptivity dependence of the keyhole depth. The welding material is 304L stainless steel, using the default material properties listed in Table 2. Absorptivities were calculated using Eq. 9 and data from Fig. 2.

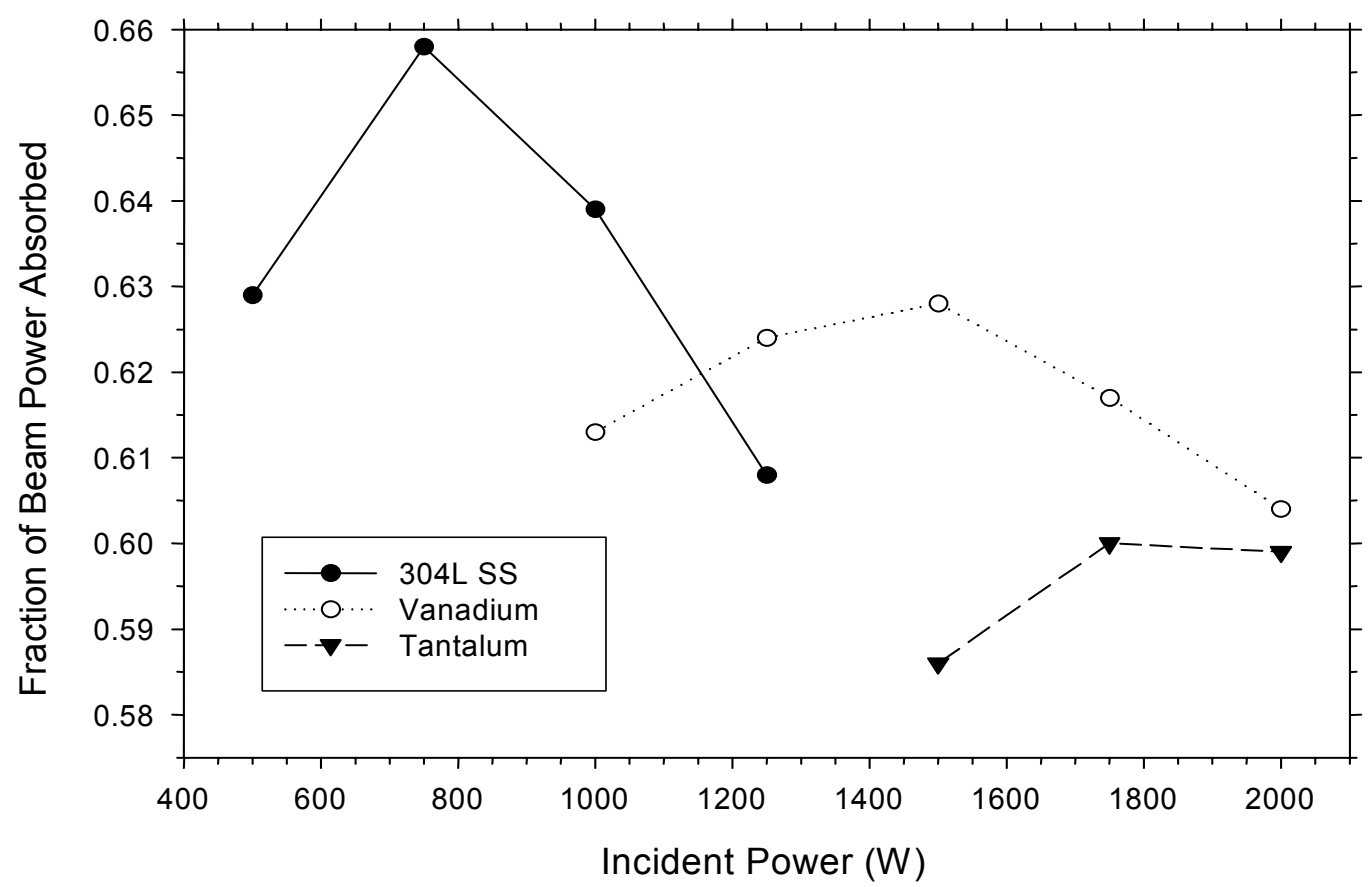

Figure 15: Calculated fraction of incident laser power absorbed by the 304L stainless steel, vanadium, and tantalum, plotted as a function of incident beam power. 